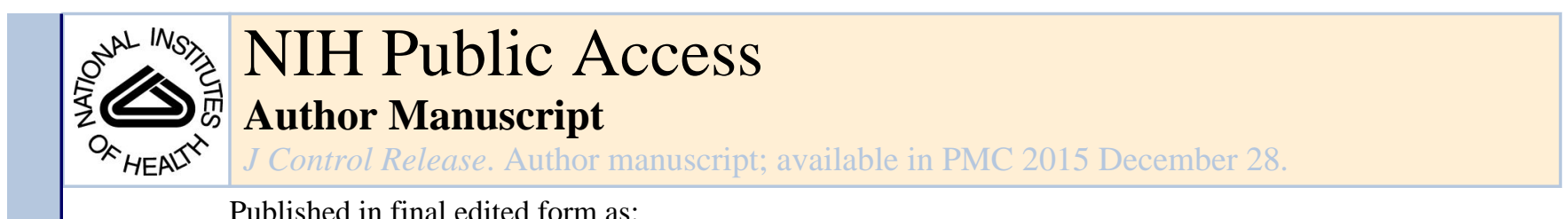

Published in final edited form as:

J Control Release. 2014 December 28; 0: 272-286. doi:10.1016/j.jconrel.2014.10.016.

\title{
An Improved D-a-Tocopherol-Based Nanocarrier for Targeted Delivery of Doxorubicin with Reversal of Multidrug Resistance
}

\author{
Jianqin Lu ${ }^{1,2,3}$, Wenchen Zhao ${ }^{1,2}$, Hao Liu ${ }^{4}$, Rebecca Marquez ${ }^{4}$, Yixian Huang ${ }^{1,2,3}$, Yifei \\ Zhang ${ }^{1,2,3}$, Jiang $\mathbf{L i}^{1,2,3}$, Wen $\mathbf{X i e}^{1,2,3}$, Raman Venkataramanan ${ }^{2}$, Liang $\mathbf{X u}^{4}$, and Song $\mathbf{L i}^{1,2,3}$ \\ ${ }^{1}$ Center for Pharmacogenetics, University of Pittsburgh, Pittsburgh, PA, 15261, USA \\ 2Department of Pharmaceutical Sciences, School of Pharmacy, University of Pittsburgh, \\ Pittsburgh, PA, 15261, USA \\ ${ }^{3}$ University of Pittsburgh Cancer Institute, University of Pittsburgh, Pittsburgh, PA, 15261, USA \\ ${ }^{4}$ Department of Molecular Biosciences, University of Kansas, Lawrence, KS, 66045 USA
}

\section{Abstract}

Nanocarriers have recently emerged as an attractive platform for delivery of various types of therapeutics including anticancer agents. Previously, we developed an improved TPGS delivery system $\left(\mathrm{PEG}_{5 \mathrm{~K}}-\mathrm{VE}_{2}\right)$ which demonstrated improved colloidal stability and greater in vivo antitumor activity. Nevertheless, the application of this system is still limited by a relatively low drug loading capacity (DLC). In this study we report that incorporation of a fluorenylmethyloxycarbonyl (Fmoc) motif at the interfacial region of $\mathrm{PEG}_{5 \mathrm{~K}}-\mathrm{VE}_{2}$ led to significant improvement of the system through the introduction of an additional mechanism of drug/carrier interaction. Doxorubicin (DOX) could be effectively loaded into $\mathrm{PEG}_{5 \mathrm{~K}}-\mathrm{Fmoc}_{-} \mathrm{VE}_{2}$ micelles at a DLC of 39.9\%, which compares favorably to most reported DOX nanoformulations. In addition, $\mathrm{PEG}_{5 \mathrm{~K}}$-Fmoc-VE2/DOX mixed micelles showed more sustained release of DOX in comparison to the counterpart without Fmoc motif. MTT assay showed that $\mathrm{PEG}_{5 \mathrm{~K}}$-Fmoc$\mathrm{VE}_{2} / \mathrm{DOX}$ exerted significantly higher levels of cytotoxicity over DOX, Doxil as well as $\mathrm{PEG}_{5 \mathrm{~K}^{-}}$ $\mathrm{VE}_{2} / \mathrm{DOX}$ in PC-3 and 4T1.2 cells. Cytotoxicity assay with NCI/ADR-RES, a drug resistant cell line, suggested that $\mathrm{PEG}_{5 \mathrm{~K}}-\mathrm{Fmoc}-\mathrm{VE}_{2}$ may have a potential to reverse the multidrug resistance, which was supported by its inhibition on P-gp ATPase. Pharmacokinetics (PK) and biodistribution studies showed an increased half-life in blood circulation and more effective tumor accumulation for DOX formulated in $\mathrm{PEG}_{5 \mathrm{~K}}-\mathrm{Fmoc}-\mathrm{VE}_{2}$ micelles. More importantly, DOX-loaded $\mathrm{PEG}_{5 \mathrm{~K}^{-}}$ Fmoc-VE $\mathrm{V}_{2}$ micelles showed an excellent safety profile with a MTD $(\sim 30 \mathrm{mg}$ DOX/kg) that is about 3 times as much as that for free DOX. Finally, superior antitumor activity was demonstrated for $\mathrm{PEG}_{5 \mathrm{~K}}-\mathrm{Fmoc}_{-} \mathrm{VE}_{2} / \mathrm{DOX}$ in both drug-sensitive (4T1.2 and PC-3) and drug-resistant (KB 8-5) tumor models compared to DOX, Doxil, and $\mathrm{PEG}_{5 \mathrm{~K}}-\mathrm{VE}_{2} / \mathrm{DOX}$.

(C) 2014 Elsevier B.V. All rights reserved.

Address correspondence to: Song Li, M.D., Ph.D., Center for Pharmacogenetics, University of Pittsburgh School of Pharmacy, 639 Salk Hall, Pittsburgh, PA 15261, Tel: 412-383-7976, Fax: 412-648-1664, sol4@ pitt.edu.

Publisher's Disclaimer: This is a PDF file of an unedited manuscript that has been accepted for publication. As a service to our customers we are providing this early version of the manuscript. The manuscript will undergo copyediting, typesetting, and review of the resulting proof before it is published in its final citable form. Please note that during the production process errors may be discovered which could affect the content, and all legal disclaimers that apply to the journal pertain. 


\section{Keywords}

Fluorenylmethyloxycarbonyl; Drug-interactive Motif; Nanomedicine; Reversal of Multidrug Resistance; Chemotherapeutics

\section{Introduction}

Doxorubicin (DOX), one of the most potent anticancer agents, has been widely used for the treatment of ovarian, breast, prostate, cervix, brain, and lung cancers. It functions by intercalating between base pairs of the DNA helix, resulting in the suppression of DNA synthesis [1-3]. In addition, doxorubicin stabilizes the topoisomerase II-DNA complex after it has broken the DNA chain for replication, which prevents the DNA double helix from being resealed and thereby arrests the process of replication [1,4]. However, its clinical application has been compromised by its limited efficacy in vivo and systemic side effects $[5,6]$. Hence, there is a need to develop an effective drug carrier to specifically deliver DOX to tumors.

In the last two decades, D-a-tocopheryl polyethylene glycol succinate (TPGS) has gained increasing attention as an ideal biomaterial in developing various drug delivery systems such as micelles, liposomes, and other nanoparticles [7-13]. TPGS is able to function as a solubilizer, emulsifier, additive, permeability enhancer as well as absorption enhancer $[14,15]$. Additionally, TPGS is capable of overcoming multidrug resistance mediated by Pgp efflux pump [15-18]. As a stand-alone micellar formulation, the performance of TPGSs is affected by the molecular weight of PEG and the molar ratio of Vitamin E/PEG in the conjugates [19]. Previously, our lab developed $\mathrm{PEG}_{5 \mathrm{~K}}-\mathrm{VE}_{2}$ nanomicelles comprising one molecule of polyethylene glycol 5000 and two molecules of Vitamin E succinate, which demonstrated improved performance in formulating and delivering paclitaxel (PTX) over other TPGS micellar formulations $\left(\mathrm{TPGS}_{5 \mathrm{~K}}, \mathrm{TPGS}_{2 \mathrm{~K}}\right.$ and $\mathrm{PEG}_{2 \mathrm{~K}}$-Vitamin $\mathrm{E}_{2}$ ) [19]. Nonetheless, this improved system still has limited drug loading capacity. This is likely due to the fact that loading of drugs into these micellar formulations is largely driven by hydrophobic interaction. Such mechanism of carrier/drug interaction, while working well for highly hydrophobic drugs, may show limited effectiveness for many moderately hydrophobic drugs. This limitation is also shared by many other existing micellar systems [19-22].

Recently, Park's group has demonstrated that inclusion of a hydrotropic molecule into the hydrophobic part of a block copolymer was able to improve the accommodation of drugs that are not entirely hydrophobic or lipophilic $[23,24]$. This was mainly due to the additional mechanism of carrier/drug interaction rendered by the hydrotropic molecules introduced. Hydrotropes, small amphiphilic molecules, are capable of solubilizing hydrophobic compounds in aqueous solutions through hydrogen bonding. Incorporation of the hydrotropic molecule into polymeric micelles led to improvement in both drug loading capacity and the colloidal stability of drug-formulated micelles.

We have recently shown that incorporation of a drug-interactive domain at the interfacial region of PEGylated lipopeptides resulted in a significant improvement in loading of 
hydrophobic drugs $[25,26]$. Among a number of functional motifs examined, fluorenylmethyloxycarbonyl (Fmoc), a commonly used amine protecting group in peptide chemistry, was found to be the most effective drug-interactive group in facilitating carrier/ drug interaction [25]. A PEGylated lipopeptide with a built-in Fmoc at the interfacial region was effective in formulating various types of therapeutic agents of diverse structures [26]. Delivery of PTX via this formulation led to significant inhibition of tumor growth in a murine breast cancer model (4T1.2) [26].

This study is focused on the development of a new TPGS-based nanomicellar system with a built-in drug interactive motif, $\mathrm{PEG}_{5 \mathrm{~K}}-\mathrm{Fmoc}-\mathrm{VE}_{2}$. We hypothesized that incorporation of Fmoc at the interfacial region of $\mathrm{PEG}_{5 \mathrm{~K}}-\mathrm{VE}_{2}$ shall greatly improve its performance in formulating and delivering hydrophobic anticancer agents. DOX was used as a model hydrophobic drug. Systematic comparison between $\mathrm{PEG}_{5 \mathrm{~K}}-\mathrm{VE}_{2}$ and $\mathrm{PEG}_{5 \mathrm{~K}}-\mathrm{Fmoc}-\mathrm{VE}_{2}$ micelles was conducted with respect to the drug loading capacity and efficiency, stability, intracellular uptake, maximum tolerated dose, as well as in vitro and in vivo antitumor efficacy. Our data showed that $\mathrm{PEG}_{5 \mathrm{~K}}-\mathrm{Fmoc}-\mathrm{VE}_{2}$ was more effective than $\mathrm{PEG}_{5 \mathrm{~K}}-\mathrm{VE}_{2}$ in forming stable mixed micelles with DOX. More importantly, DOX-loaded $\mathrm{PEG}_{5 \mathrm{~K}}$-Fmoc$\mathrm{VE}_{2}$ micelles exhibited significantly improved antitumor activity in vivo.

\section{Materials and methods}

\section{Materials}

Doxorubicin hydrochloride (98\%) (DOX.HCl) was purchased from AK Scientific Inc. (CA, USA). Doxil was purchased from Avanti ${ }^{\circledR}$ Polar Lipids (AL, USA). Methoxy-PEG 5,000- $^{-}$ $\mathrm{OH}$, succinate anhydride, Boc-lys-(Boc)-OH, Fmoc-lys-(Boc)-OH, 3-(4,5dimethylthiazol-2-yl)-2,5-diphenyl tetrazolium bromide (MTT), aspartic acid, trypsin-EDTA solution, Triton X-100, and Dulbecco's Modified Eagle's Medium (DMEM) were all purchased from Sigma-Aldrich (MO, USA). D-alpha-tocopherol was purchased from Tokyo Chemical Industry (OR, USA). N,N'-dicyclohexylcarbodiimide (DCC) was purchased from Alfa Aesar (MA, USA). 4-Dimethylaminopyridine (DMAP) was purchased from Calbiochem-Novabiochem Corporation (CA, USA). Fetal bovine serum (FBS) and penicillin-streptomycin solution were from Invitrogen (NY, USA). All solvents used in this study were HPLC grade.

\section{Synthesis of $\mathrm{PEG}_{5 \mathrm{~K}}-\mathrm{Fmoc}-\mathrm{VE}_{2}$ and $P \mathrm{PG}_{5 \mathrm{~K}}-\mathrm{VE}_{2}$}

$\mathrm{PEG}_{5 \mathrm{~K}}-\mathrm{VE}_{2}$ was synthesized as reported previously [27]. $\mathrm{PEG}_{5 \mathrm{~K}}-\mathrm{Fmoc}-\mathrm{VE}_{2}$ was synthesized as follows: First, Fmoc-lys(Boc)-OH (4 eq.) was coupled to the terminal -OH of $\mathrm{MeO}-\mathrm{PEG}_{5 \mathrm{~K}}-\mathrm{OH}$ with the assistance of DCC (4 eq.) and DMAP (0.2 eq.) in DCM overnight. The resulting $\mathrm{PEG}_{5 \mathrm{~K}}$-Fmoc-lys-(Boc) was washed and precipitated thrice by cold ethanol and ether, respectively. Boc group was then removed with 50\% trifluoroacetic (TFA) acid in DCM for $2 \mathrm{~h}$, and the resulting ( $\mathrm{PEG}_{5 \mathrm{~K}}-\mathrm{Fmoc}-\mathrm{lys}-\mathrm{NH}_{2}$ ) was precipitated by cold ethanol and ether thrice, respectively. Boc-lys(Boc)-OH (2 eq.) was then conjugated to the terminal $-\mathrm{NH}_{2}$ of $\mathrm{PEG}_{5 \mathrm{~K}}$-Fmoc-lys via DCC (2 eq.) and DMAP (0.1 eq.) as coupling reagents in DCM overnight. The $\mathrm{PEG}_{5 \mathrm{~K}}-\mathrm{Fmoc}-\mathrm{di}-\mathrm{Boc}$ obtained was precipitated and washed thrice with cold ethanol and ether, respectively. Boc groups in $\mathrm{PEG}_{5 \mathrm{~K}}$-Fmoc-di-Boc 
were removed by $50 \%$ TFA in DCM for $2 \mathrm{~h}$, and the resulting $\left(\mathrm{PEG}_{5 \mathrm{~K}}-\mathrm{Fmoc}-\mathrm{di}-\mathrm{NH}_{2}\right)$ was purified via precipitation in cold ethanol and ether, respectively. Finally, Vitamin E succinate (4 eq.) was coupled onto the deprotected amino groups of $\mathrm{PEG}_{5 \mathrm{~K}}-\mathrm{Fmoc}-\mathrm{di}-\mathrm{NH}_{2}$ with DCC (4 eq.) and DMAP (0.2 eq.) as coupling reagents in DCM overnight to produce $\mathrm{PEG}_{5 \mathrm{~K}}-\mathrm{Fmoc}-\mathrm{VE}_{2}$. The resulting $\mathrm{PEG}_{5 \mathrm{~K}}-\mathrm{Fmoc}-\mathrm{VE}_{2}$ was further purified via precipitation in cold ethanol and ether, respectively. The purified $\mathrm{PEG}_{5 \mathrm{~K}}-\mathrm{Fmoc}-\mathrm{VE}_{2}$ was dried under vacuum prior to use. The identity and purity of $\mathrm{PEG}_{5 \mathrm{~K}}-\mathrm{Fmoc}-\mathrm{VE}_{2}$ were confirmed by ${ }^{1}$ NMR, MALDI-TOF and HPLC.

\section{Preparation and characterization of DOX-loaded micelles}

DOX $\mathrm{HCl}$ was first neutralized by 3 molar eq. triethylamine in $\mathrm{CHCl}_{3} / \mathrm{MeOH}(1: 1$. v:v) to eliminate $\mathrm{HCl}$. $\mathrm{PEG}_{5 \mathrm{~K}}-\mathrm{Fmoc}-\mathrm{VE}_{2} / \mathrm{DOX}$ mixed micelles were prepared as described before [27]. Briefly, $\mathrm{PEG}_{5 \mathrm{~K}}-\mathrm{Fmoc}_{-} \mathrm{VE}_{2}\left(10 \mathrm{mM}\right.$ in $\left.\mathrm{CHCl}_{3}\right)$ was mixed with DOX $(10 \mathrm{mM}$ in $\left.\mathrm{CHCl}_{3} / \mathrm{MeOH}\right)$ under different carrier/drug molar ratios. The mixture was first dried by nitrogen flow to form a thin dry film. The dry film was further dried under vacuum for $4 \mathrm{~h}$ to remove any traces of remaining solvent. The film was then reconstituted in saline without sonication. The micellar formulations were filtered through a $0.22 \mu \mathrm{m}$ filter prior to characterization. The DOX-loaded $\mathrm{PEG}_{5 \mathrm{~K}}-\mathrm{VE}_{2}$ micelles were similarly prepared as mentioned above. The mean diameter and size distribution of micelles with or without loaded drug were evaluated by dynamic light scattering (DLS). The morphology of DOXfree or DOX-loaded micelles was evaluated under TEM. The concentration of DOX in micelles was assessed by HPLC-Fluorescence detection (Excitation: $490 \mathrm{~nm}$; Emission: 590 $\mathrm{nm}$ ). The drug loading capacity (DLC) and drug loading efficiency (DLE) were calculated according to the following formula:

$D L C(\%)=[$ weight of drug loaded $\div$ (weight of polymer in the micelles without free DOX+weight of drug loaded $)]$ $D L E(\%)=($ weight of loaded drug $\div$ weight of input drug $) \times 100 \%$

\section{DOX release kinetics}

The cumulative release kinetics of DOX in vitro was conducted by dialysis technique using DPBS (PH $=7.4)$ containing $0.5 \%(w / v)$ Tween 80 as the release medium. Free DOX was utilized as a control. Two $\mathrm{mL}$ of DOX-loaded $\mathrm{PEG}_{5 \mathrm{~K}}-\mathrm{VE}_{2}$ or $\mathrm{PEG}_{5 \mathrm{~K}}-\mathrm{Fmoc}_{-\mathrm{VE}}$ micelles (1 $\mathrm{mg} \mathrm{DOX} / \mathrm{mL}$ ) were sealed in dialysis tubes ( $\mathrm{MWCO}=12 \mathrm{KDa}$, Spectrum Laboratories). The dialysis tubes were immersed in $500 \mathrm{~mL}$ release medium in a beaker capped with parafilm. The beakers were kept in an incubator shaker at $100 \mathrm{rpm}$ and $37^{\circ} \mathrm{C}$. At predetermined time points, aliquots of samples were collected, diluted, and filtered through a $0.22 \mu \mathrm{m}$ filter prior to analysis by HPLC with the detector set at $490 \mathrm{~nm}$. Values were reported as the means from triplicate samples.

\section{Fluorescence quenching studies}

$\mathrm{PEG}_{5 \mathrm{~K}}-\mathrm{VE}_{2} / \mathrm{DOX}$ and $\mathrm{PEG}_{5 \mathrm{~K}}-\mathrm{Fmoc}-\mathrm{VE}_{2} / \mathrm{DOX}$ were prepared at varying carrier to drug molar ratio as mentioned above. To examine fluorescence quenching of the carriers, the molar concentrations of carriers were kept constant for comparison. In another set of experiment, DOX concentration was kept constant to examine the fluorescence quenching of 
DOX. The samples were placed into a 96-well plate, and the fluorescence intensity of carriers was recorded on a Synergy H1 Hybrid reader (BioTek), using an excitation wavelength of $270 \mathrm{~nm}$ and emission wavelength from $300-500 \mathrm{~nm}$. The fluorescence intensity of DOX was examined using an excitation wavelength of $480 \mathrm{~nm}$ and emission wavelength from $510-650 \mathrm{~nm}$.

\section{UV absorbance spectroscopy of DOX}

The absorption spectra were collected using Varian Cary 50 Bio UV-Visible Spectrophotometer over a wavelength ranging from 300 to $800 \mathrm{~nm}$. $\mathrm{PEG}_{5 \mathrm{~K}}-\mathrm{VE}_{2} / \mathrm{DOX}$ and $\mathrm{PEG}_{5 \mathrm{~K}}-\mathrm{Fmoc}-\mathrm{VE}_{2} / \mathrm{DOX}$ were prepared at a molar ratio of 2.5/1. All samples in distilled water were loaded into a quartz cell and measured against distilled water as the reference.

\section{Fourier transform infrared spectroscopy (FT-IR)}

FT-IR of DOX, DOX-loaded $\mathrm{PEG}_{5 \mathrm{~K}}-\mathrm{VE}_{2}$, and DOX-loaded $\mathrm{PEG}_{5 \mathrm{~K}}-\mathrm{Fmoc}-\mathrm{VE}_{2}$ was evaluated using a VERTEX 70/70v FT-IR spectrometer (Bruker) to determine the hydrogen bonding of carrier/carrier and carrier/drug in the frequency of $4997-500 \mathrm{~cm}^{-1}(\mathrm{KBr}$ pellet).

\section{Hemolytic effect of $\mathrm{PEG}_{5 \mathrm{~K}}-\mathrm{Fmoc}-\mathrm{VE}_{2}$}

The hemolytic activity of $\mathrm{PEG}_{5 \mathrm{~K}}-\mathrm{Fmoc}-\mathrm{VE}_{2}$ was examined using rat red blood cells (RBCs) following our published method [27].

\section{Cell culture}

Mouse breast cancer cell line, 4T1.2, human prostate cancer cell line, PC-3, and adriamycin (ADR)-resistant cell line, NCI/ADR-RES, were used in this work. All cell lines were cultured in DMEM containing 10\% FBS and 1\% penicillin-streptomycin in a humidified environment at $37^{\circ} \mathrm{C}$ with $5 \% \mathrm{CO}_{2}$.

\section{Animals}

Male and female and nude mice of 6-8 weeks of age were purchased from Harlan (Livermore, CA). Female BALB/c mice of 10-12 weeks of age were purchased from Charles River (Davis, CA). All animals were housed under pathogen-free conditions according to AAALAC (Association for Assessment and Accreditation of Laboratory Animal Care) guidelines. All animal-related experiments were performed in full compliance with institutional guidelines and approved by the Animal Use and Care Administrative Advisory Committee at the University of Pittsburgh.

\section{In vitro cytotoxicity}

The cytotoxicity of DOX formulated in $\mathrm{PEG}_{5 \mathrm{~K}}-\mathrm{VE}_{2}$ or $\mathrm{PEG}_{5 \mathrm{~K}}-\mathrm{Fmoc}-\mathrm{VE}_{2}$ was evaluated in 4T1.2, PC-3, and NCI/ADR-RES cell lines, in comparison to free DOX and Doxil. Briefly, cells were seeded in 96-well plates followed by overnight attachment. Then cells were treated by different DOX formulations of varied concentrations. Free $\mathrm{PEG}_{5 \mathrm{~K}}-\mathrm{VE}_{2}$ or $\mathrm{PEG}_{5 \mathrm{~K}}-\mathrm{Fmoc}-\mathrm{VE}_{2}$, at concentrations equivalent to those of carriers in the corresponding DOX formulation groups, was also added into cells. Cells were incubated for $72 \mathrm{~h}$ and cell viability was determined by MTT assay [19]. 


\section{Intracellular uptake}

$3 \times 10^{5} \mathrm{NCI} / \mathrm{ADR}-\mathrm{RES}$ cells/well were seeded into 6-well plates and incubated overnight prior to any treatment. Then cells were treated with free DOX, Doxil, and DOX-loaded $\mathrm{PEG}_{5 \mathrm{~K}}-\mathrm{VE}_{2}$ and $\mathrm{PEG}_{5 \mathrm{~K}}-\mathrm{Fmoc}-\mathrm{VE}_{2}$, respectively at a DOX concentration of $6 \mu \mathrm{g} / \mathrm{mL}$. Cells were then incubated for $1 \mathrm{~h}$ or $3 \mathrm{~h}$ at $37^{\circ} \mathrm{C}$. After that, cells were washed three times with cold PBS and fixed with $4 \%$ paraformaldehyde for $30 \mathrm{~min}$. The nuclei were then stained by Hoechst 33342 for $5 \mathrm{~min}$. Subsequently, cells were washed thrice with cold PBS. The intracellular uptake of DOX in various formulations was observed under confocal laser scanning microscopy (CLSM, FluoView 1000, Olympus, Japan).

Quantitative cellular uptake of various DOX formulations was evaluated by flow cytometry. Briefly, NCI/ADR-RES cells were prepared as described above. Following treatment with various DOX formulations at $37^{\circ} \mathrm{C}$ for $1 \mathrm{~h}$ or $3 \mathrm{~h}$, cells were washed with cold PBS thrice, and resuspended in $500 \mu \mathrm{L}$ PBS prior to the flow cytometry analysis with $\mathrm{CyAn}{ }^{\mathrm{TM}} \mathrm{ADP}$ Analyzer (Beckman Coulter, Inc.). Cell-associated DOX was excited with an argon laser $(480 \mathrm{~nm})$, and fluorescence was detected at $570 \mathrm{~nm}$. Twenty-thousand events were collected for each sample.

\section{P-gp ATPase assay}

The effect of $\mathrm{PEG}_{5 \mathrm{~K}}-\mathrm{Fmoc}-\mathrm{VE}_{2}$ conjugate on P-gp was investigated through examining its impact on a verapamil-stimulated ATPase activity as reported previously [27].

\section{Near infrared fluorescence (NIRF) imaging}

The tumor-targeting efficiency and biodistribution of $\mathrm{PEG}_{5 \mathrm{~K}}-\mathrm{Fmoc}-\mathrm{VE}_{2}$ in vivo was examined using a near infrared fluorescence dye, DiD. Nude mice bearing PC-3 xenograft were employed in this study. Two hundred $\mu \mathrm{L}$ of DiD-loaded $\mathrm{PEG}_{5 \mathrm{~K}}-\mathrm{Fmoc}-\mathrm{VE}_{2}$ (DiD concentration in the formulation was $0.4 \mathrm{mg} / \mathrm{mL}$ ) was i.v. injected into each mouse. At different time points $(0.5 \mathrm{~h}, 6 \mathrm{~h}, 24 \mathrm{~h}, 48 \mathrm{~h}, 72 \mathrm{~h}$ and $96 \mathrm{~h})$ post-injection, mice were imaged under Carestream Molecular Imaging System (Carestream Health, Inc.) with the excitation at $630 \mathrm{~nm}$ and the emission at $700 \mathrm{~nm}$ using an exposure time of $60 \mathrm{~s}$. After $96 \mathrm{~h}$, mice were euthanized and tumors and major organs were excised and imaged with Carestream Molecular Imaging System. The tissue distribution of $\mathrm{DiD}$ in tumors and other organs was quantified by measuring the signal intensity at the region of interest.

\section{Pharmacokinetics and biodistribution}

$\mathrm{PEG}_{5 \mathrm{~K}}-\mathrm{VE}_{2} / \mathrm{DOX}, \mathrm{PEG}_{5 \mathrm{~K}}-\mathrm{Fmoc}_{-} \mathrm{VE}_{2} / \mathrm{DOX}$, and free DOX were administered i.v. at a dose of $5 \mathrm{mg} \mathrm{DOX} / \mathrm{kg}$ in $200 \mu \mathrm{L}$ saline $(\mathrm{n}=3)$. At predetermined time points ( $3 \mathrm{~min}, 8 \mathrm{~min}, 15$ min, 30 min, $45 \mathrm{~min}, 1 \mathrm{~h}, 2 \mathrm{~h}, 4 \mathrm{~h}, 8 \mathrm{~h}$ and $12 \mathrm{~h}$ ), blood was obtained from mice using a heparinized capillary tube. Plasma samples were isolated from the blood by centrifuging at $3000 \mathrm{rpm}$ for $10 \mathrm{~min}$. DOX in plasma was extracted via an extraction buffer (10\% Triton $\mathrm{X}-100$, deionized water, and isopropanol at a volumetric ratio of 1:2:15). The concentration of DOX at various time points was measured by HPLC with the detector set at $490 \mathrm{~nm}$ (Waters Alliance 2695 Separations Module combined with Waters 2998 Photodiode Array Detector, Waters Symmetry C18 $5 \mu \mathrm{m}$ 4.6*250 mm column, mobile phase: 80\% MeOH: 
$20 \% \mathrm{H}_{2} \mathrm{O}$ isocrate, flow rate: $\left.0.6 \mathrm{~mL} / \mathrm{min}\right)$. Pharmacokinetic parameters such as $\mathrm{t}_{1 / 2}$, volume of distribution $\left(\mathrm{V}_{d}\right)$, area under the curve (AUC), and clearance $(\mathrm{CL})$ were calculated by fitting the blood DOX concentrations to a non-compartment model using Phoenix WinNonlin.

For biodistribution study, free DOX and DOX-loaded micelles were i.v. injected into 4T1.2 tumor-bearing mice at a dose of $5 \mathrm{mg}$ DOX/kg, respectively $(\mathrm{n}=3)$. At $24 \mathrm{~h}$ post-injection, major organs (liver, spleen, lung, heart, and kidney), tumors, and blood were collected from the mice. Tissues were then homogenized utilizing a Power Gen 500 homogenizer (Fisher Scientific), in which $100 \mathrm{mg}$ tissues were mixed with $900 \mu \mathrm{L}$ extraction buffer, and DOX was extracted overnight at $-20{ }^{\circ} \mathrm{C}$. The samples were centrifuged at 3,000 rpm for $10 \mathrm{~min}$, and the supernatant was then dried and dissolved in $400 \mu \mathrm{L} 75 \% \mathrm{MeOH}$. Subsequently, the samples were further centrifuged at 14,500 rpm for $5 \mathrm{~min}$ to remove undissolved materials prior to HPLC measurement as mentioned above. The $\%$ injected dose and the $\%$ injected dose per gram (tissue) were calculated using the following equations:

$$
\begin{gathered}
\% \text { injected dose }=(\text { dose in blood or in a tissue sample }) \div \text { injected dose } \times 100 \% \\
\frac{(\% \text { injected dose })}{(\text { g tissue })}=(\% \text { injected dose }) \div[\text { weight of tissue }(g)]
\end{gathered}
$$

\section{Maximum tolerated dose (MTD)}

Groups of 3 female BALB/c mice were treated intravenously with free DOX $(5,10$, and 15 $\mathrm{mg}$ DOX/kg), DOX-loaded $\mathrm{PEG}_{5 \mathrm{~K}}-\mathrm{VE}_{2}(5,10,15,20$, and $30 \mathrm{mg} \mathrm{DOX} / \mathrm{kg})$ or DOX-loaded $\mathrm{PEG}_{5 \mathrm{~K}}-\mathrm{Fmoc}_{-\mathrm{VE}_{2}}(10,15,20,25,30$, and $35 \mathrm{mg}$ DOX/kg), respectively. Changes in body weight and general signs, and survival of mice were followed daily for two weeks. The MTD was determined as the maximal dose that causes neither mouse mortality nor greater than $15 \%$ loss in body weight and other significant changes in the general movement and signs within the entire period of the experiment.

\section{In vivo antitumor efficacy}

Both drug-sensitive (4T1.2 and PC-3) and drug-resistant (KB 8-5) tumor models were used to evaluate the therapeutic effect of DOX formulated in $\mathrm{PEG}_{5 \mathrm{~K}}-\mathrm{VE}_{2}$ and $\mathrm{PEG}_{5 \mathrm{~K}}-\mathrm{Fmoc}-\mathrm{VE}_{2}$ micelles. 4T1.2 is an aggressive syngeneic murine breast cancer model and PC-3 and KB 8-5 are human prostate and cervical cancer xenograft model, respectively.

In the breast cancer model, $1 \times 10^{5} 4 \mathrm{~T} 1.2$ cells in $200 \mu \mathrm{L}$ PBS were inoculated s.c. at the right flank of female BALB/c mice. Various treatments were started when tumors reached a tumor volume around $50 \mathrm{~mm}^{3}$ and this day was named as day 1 . On day 1 , mice were randomly divided into six groups $(n=5)$ and received i.v. administration of free DOX (10 $\mathrm{mg}$ DOX/kg), Doxil (10 mg DOX/kg), DOX-loaded PEG ${ }_{5 \mathrm{~K}}-\mathrm{VE}_{2}(10 \mathrm{mg}$ DOX/kg), DOXloaded $\mathrm{PEG}_{5 \mathrm{~K}}-\mathrm{Fmoc}_{-\mathrm{VE}}\left(10 \mathrm{mg}\right.$ DOX/kg), DOX-loaded $\mathrm{PEG}_{5 \mathrm{~K}}-\mathrm{Fmoc}_{2} \mathrm{VE}^{2}(20 \mathrm{mg}$ $\mathrm{DOX} / \mathrm{kg}$ ) and saline, respectively on days 1,4 , and 7 . Tumor sizes were monitored with a digital caliper on days $1,4,7,10,12,15,18,21$, and 25 and calculated based on the formula: $\left(\mathrm{L} \times \mathrm{W}^{2}\right) / 2$, where $\mathrm{L}$ and $\mathrm{W}$ are length and width of each tumor. To compare between groups, relative tumor volume (RTV) was calculated at each measurement time point (where RTV equals the tumor volume at a given time point divided by the tumor volume prior to first 
treatment). Mice were sacrificed if tumors reached $2000 \mathrm{~mm}^{3}$ or developed ulceration.

Tumor growth inhibition rate (IR) was also calculated and defined as following:

\section{$I R(\%)=(1-$ relative tumor volume in the treated group $\div$ relative tumor volume in the saline group $) \times 100 \%$}

Furthermore, to monitor the systemic toxicity, the body weights of mice were measured at the time of tumor size measurement.

In PC- 3 xenograft tumor model, $2 \times 10^{6}$ PC- 3 cells in $200 \mu \mathrm{L}$ PBS were inoculated s.c. at the right flank in male nude mice. Treatments were initiated when tumors in the mice reached a volume around $50 \mathrm{~mm}^{3}$ and different groups $(\mathrm{n}=6)$ were similarly treated as mentioned above on days 1,4 , and 7 . Tumor size and body weight were monitored as described above.

In KB 8-5 xenograft tumor model, $5 \times 10^{6}$ cells were inoculated s.c at the right flank of female nude mice. When the tumor volume reached approximately $50 \mathrm{~mm}^{3}, 6$ groups of mice $(\mathrm{n}=5)$ were treated with saline, DOX $(5 \mathrm{mg} / \mathrm{kg})$, DOX $(7.5 \mathrm{mg} / \mathrm{kg}), \mathrm{PEG}_{5 \mathrm{~K}}-\mathrm{VE}_{2} / \mathrm{DOX}$ (5 mg/kg), $\mathrm{PEG}_{5 \mathrm{~K}}-\mathrm{Fmoc}-\mathrm{VE}_{2} / \mathrm{DOX}(5 \mathrm{mg} / \mathrm{kg})$, and $\mathrm{PEG}_{5 \mathrm{~K}}-\mathrm{Fmoc}-\mathrm{VE}_{2} / \mathrm{DOX}(7.5 \mathrm{mg} / \mathrm{kg})$, respectively, on days 1,4 , and 7 . Tumor size and body weight were monitored very three days.

\section{Statistical analysis}

In all statistical analyses, the significance level was set at a probability of $P<0.05$. All results were reported as the mean \pm standard deviation (SD) unless otherwise indicated. Statistical analysis was performed by using the Student's t-test for two groups, and one-way ANOVA for multiple groups, followed by Newman-Keuls test if $P<0.05$.

\section{Results and discussion}

\section{Coupling of Fmoc motif to $\mathrm{PEG}_{5 \mathrm{~K}}-\mathrm{VE}_{2}$ at the interfacial region}

In an effort to improve the TPGS-based micellar formulation, we have previously synthesized and characterized four PEG-Vitamin E conjugates that vary in the molecular weight of PEG (2 vs 5K) and the molar ratio of PEG/Vitamin E (1/1 vs 1/2) [27]. Our results showed that the conjugate with one molecule of $\mathrm{PEG}_{5 \mathrm{~K}}$ and two molecules of Vitamin $\mathrm{E}$ $\left(\mathrm{PEG}_{5 \mathrm{~K}}-\mathrm{VE}_{2}\right.$ ) was most effective in formulating and delivering PTX to tumor cells in vitro and in vivo. In this study, Fmoc was incorporated into $\mathrm{PEG}_{5 \mathrm{~K}}-\mathrm{VE}_{2}$ at the interfacial region to further improve the performance of this carrier. Our recent study has shown that Fmoc is a highly effective drug-interactive motif and that incorporation of this motif into lipid-core micelles greatly facilitates the carrier/drug interaction. The synthesis route of $\mathrm{PEG}_{5 \mathrm{~K}}-\mathrm{Fmoc}-$ $\mathrm{VE}_{2}$ was presented in Scheme 1. Briefly, $\mathrm{MeO}-\mathrm{PEG}_{5 \mathrm{~K}}-\mathrm{OH}$ was first reacted with Fmoc-lys(Boc)-OH to yield PEG $_{5 \mathrm{~K}}$-Fmoc-lys-(Boc) followed by the removal of Boc to expose the terminal $\mathrm{NH}_{2}$. $\mathrm{PEG}_{5 \mathrm{~K}}-\mathrm{Fmoc}-\mathrm{lys}-\mathrm{NH}_{2}$ was then coupled to Boc-lys-(Boc) to generate $\mathrm{PEG}_{5 \mathrm{~K}}$-Fmoc-di-Boc followed by the removal of Boc groups. Finally, Vitamin E succinate was conjugated to $\mathrm{PEG}_{5 \mathrm{~K}}-\mathrm{Fmoc}-\mathrm{di}-\mathrm{NH}_{2}$ to produce $\mathrm{PEG}_{5 \mathrm{~K}}-\mathrm{Fmoc}-\mathrm{VE}_{2}$. The chemical identity of the final product was verified by ${ }^{1}$ NMR (Fig. 2) and MALDI-TOF (Fig. S1). HPLC showed that the purity of the conjugate was $97.8 \%$ (Fig. S2). 


\section{Physicochemical characterizations of DOX-free and DOX-loaded PEG 5 K-Fmoc-VE 2 micelles}

In aqueous solution, $\mathrm{PEG}_{5 \mathrm{~K}}-\mathrm{Fmoc}-\mathrm{VE}_{2}$ readily self-assembled into elongated worm-like nanoassemblies with a particle size around $55 \mathrm{~nm}$ as determined by DLS analysis (Fig. 1A, Tab. 1). This is in contrast to $\mathrm{PEG}_{5 \mathrm{~K}}-\mathrm{VE}_{2}$ without Fmoc motif that formed typical spherical particles (Fig. S3A). A similar result was found in a recent study with an Fmoc-containing PEG-lipopeptide [26]. The formation of the filamentous structure is likely attributed to the Fmoc-mediated strong interaction among the carrier molecules since Fmoc-containing peptides are known to self-assemble into nanofibers or nanotubues [28-30]. However, in the case of Fmoc-containing PEG-lipopeptide, both lipid and Fmoc contributed to the formation of filamentous structure as the counterpart without lipid formed spherical structure [26]. It is likely that both the benzene ring and the alkane chain of Vitamin $\mathrm{E}$ are involved in the formation of filamentous structure.

Interestingly, following the incorporation of DOX into $\mathrm{PEG}_{5 \mathrm{~K}}-\mathrm{Fmoc}_{-} \mathrm{VE}_{2}$, the morphology of the nanoparticles started to change drastically from filamentous (Fig. 1A) to spherical structure (Fig. 1B). This is likely due to the fact that the carrier/drug interaction impacted the interaction among the carrier molecules themselves following the incorporation of DOX, leading to the structural rearrangement. Both $\mathrm{PEG}_{5 \mathrm{~K}}-\mathrm{VE}_{2}$ and $\mathrm{DOX}$-loaded $\mathrm{PEG}_{5 \mathrm{~K}}-\mathrm{VE}_{2}$ micelles were found to be spherical with a diameter around $20 \mathrm{~nm}$ (Fig. S3).

Tab. 1 compares the DOX loading capacity (DLC) and efficiency (DLE) of $\mathrm{PEG}_{5 \mathrm{~K}}-\mathrm{VE}_{2}$ and $\mathrm{PEG}_{5 \mathrm{~K}}-\mathrm{Fmoc}-\mathrm{VE}_{2}$. For $\mathrm{PEG}_{5 \mathrm{~K}}-\mathrm{VE}_{2}$, a minimal carrier/drug molar ratio of $2.5 / 1$ was needed to form stable mixed micelles with DOX. In contrast, only a carrier/drug ratio of $0.1 / 1$ was needed for $\mathrm{PEG}_{5 \mathrm{~K}}-\mathrm{Fmoc}-\mathrm{VE}_{2}$ to form stable mixed micelles with DOX. At this ratio, the DLC for $\mathrm{PEG}_{5 \mathrm{~K}}-\mathrm{Fmoc}-\mathrm{VE}_{2}$ was $39.9 \%$ which is about 13 -fold higher than that (2.9\%) for $\mathrm{PEG}_{5 \mathrm{~K}}-\mathrm{VE}_{2}$. Increasing the carrier/drug ratio was associated with a further increase in both DLE and the colloidal stability of the DOX-loaded micelles.

To confirm whether DOX was indeed incorporated into the $\mathrm{PEG}_{5 \mathrm{~K}}-\mathrm{Fmoc}-\mathrm{VE}_{2}$ nanoassemblies, ${ }^{1} \mathrm{NMR}$ studies were conducted for a number of samples including free DOX in $\mathrm{D}_{2} \mathrm{O}, \mathrm{PEG}_{5 \mathrm{~K}}-\mathrm{Fmoc}-\mathrm{VE}_{2}$ in $\mathrm{D}_{2} \mathrm{O}$ or DMSO, and DOX formulated in $\mathrm{PEG}_{5 \mathrm{~K}}-\mathrm{Fmoc}-$ $\mathrm{VE}_{2}$ in $\mathrm{D}_{2} \mathrm{O}$. The concentration of DOX was kept at $1 \mathrm{mg} / \mathrm{mL}$. As shown in Fig. 2, free DOX showed a ${ }^{1} \mathrm{H}$ NMR spectrum in $\mathrm{D}_{2} \mathrm{O}$ that was consistent with data from literature [31]. A ${ }^{1} \mathrm{H}$ NMR spectrum was discerned for $\mathrm{PEG}_{5 \mathrm{~K}}-\mathrm{Fmoc}_{-} \mathrm{VE}_{2}$ in DMSO that matched to its structure (Fig. 2). However, when the ${ }^{1} \mathrm{H}$ NMR spectrum of $\mathrm{PEG}_{5 \mathrm{~K}}-\mathrm{Fmoc}_{-} \mathrm{VE}_{2}$ was collected in $\mathrm{D}_{2} \mathrm{O}$, the VE signals (0.5-3 ppm) and Fmoc signals (7-8.5 ppm) were substantially suppressed (Fig. 2). This could be ascribed to the self-assembling process of $\mathrm{PEG}_{5 \mathrm{~K}}-\mathrm{Fmoc}-\mathrm{VE}_{2}$, as VE and Fmoc are hydrophobic and aggregated inward, while the highly hydrophilic PEG is oriented outward into the water phase, resulting in the shielding of the signals of VE and Fmoc by PEG. Similarly, a shielding of VE and Fmoc signals was observed when $\mathrm{PEG}_{5 \mathrm{~K}}-\mathrm{Fmoc}-\mathrm{VE}_{2} / \mathrm{DOX}$ was examined in $\mathrm{D}_{2} \mathrm{O}$ (Fig. 2). In addition, the typical spectrum of DOX was barely visible, indicating that DOX was effectively encapsulated into the interior core of $\mathrm{PEG}_{5 \mathrm{~K}}-\mathrm{Fmoc}-\mathrm{VE}_{2}$ micelles. Individual NMRs for DOX in DMSO or $\mathrm{D}_{2} \mathrm{O}, \mathrm{PEG}_{5 \mathrm{~K}}-\mathrm{Fmoc}_{-\mathrm{VE}_{2}}$ in DMSO or $\mathrm{D}_{2} \mathrm{O}$, and $\mathrm{PEG}_{5 \mathrm{~K}}-\mathrm{Fmoc}-\mathrm{VE}_{2} / \mathrm{DOX}$ 
in DMSO or $\mathrm{D}_{2} \mathrm{O}$ are provided in Fig. S4, Fig. S5, Fig. S6, Fig. S7, Fig. S8, Fig. S9, respectively.

\section{DOX release kinetics in vitro}

To further understand the stability of DOX-loaded nanomicelles, the in vitro release kinetics of DOX was evaluated with dialysis method using DPBS $(\mathrm{PH}=7.4)$ containing $0.5 \%(\mathrm{w} / \mathrm{v})$ Tween 80 as the release medium. Free DOX was employed as a control. As shown in Fig. 3, $\mathrm{PEG}_{5 \mathrm{~K}}-\mathrm{VE}_{2} / \mathrm{DOX}$ micelles exhibited significantly slower release kinetics over free DOX. During the first $9 \mathrm{~h}, 92.14 \%$ of DOX was released in the free DOX group, which was substantially higher than that in $\mathrm{PEG}_{5 \mathrm{~K}}-\mathrm{VE}_{2}$ micelles (36.57\%). Notably, after introducing Fmoc group into $\mathrm{PEG}_{5 \mathrm{~K}}-\mathrm{VE}_{2}$, the release rate of DOX was further reduced. In addition, there was essentially no initial burst release for DOX-loaded $\mathrm{PEG}_{5 \mathrm{~K}}-\mathrm{Fmoc}-\mathrm{VE}_{2}$ nanoassemblies. Furthermore, DOX formulated in $\mathrm{PEG}_{5 \mathrm{~K}}-\mathrm{Fmoc}-\mathrm{VE}_{2}$ exhibited significantly slower DOX release over $\mathrm{PEG}_{5 \mathrm{~K}}-\mathrm{VE}_{2} / \mathrm{DOX}$ during the entire period. The amount of released DOX after $74 \mathrm{~h}$ was only $36.45 \%$ for $\mathrm{PEG}_{5 \mathrm{~K}}-\mathrm{Fmoc}_{-} \mathrm{VE}_{2} / \mathrm{DOX}$ mixed micelles, which is significantly less than that for free DOX $(96.35 \%)$ and $\mathrm{PEG}_{5 \mathrm{~K}}-\mathrm{VE}_{2} / \mathrm{DOX}$ (58.44\%). The significantly slower and controlled release of DOX in DOX-loaded $\mathrm{PEG}_{5 \mathrm{~K}^{-}}$ Fmoc- $\mathrm{VE}_{2}$ formulation may be attributed to the strong interactions between the carrier and DOX as well as among the carrier molecules themselves.

\section{Mechanism of interacrions between carrier and payload}

The significantly improved DLC of $\mathrm{PEG}_{5 \mathrm{~K}}-\mathrm{Fmoc}-\mathrm{VE}_{2}$ over $\mathrm{PEG}_{5 \mathrm{~K}}-\mathrm{VE}_{2}$ suggests a role of Fmoc/DOX interaction in the formation of $\mathrm{PEG}_{5 \mathrm{~K}}-\mathrm{Fmoc}-\mathrm{VE}_{2} / \mathrm{DOX}$ mixed micelles. To test this hypothesis, we examined the Fmoc/DOX interaction via fluorescence quenching assay. As shown in Fig. 4A, there is a distinct fluorescence peak at $310 \mathrm{~nm}$, which is consistent with the fluorescence spectrum of Fmoc [32]. Incorporation of DOX into $\mathrm{PEG}_{5 \mathrm{~K}}-\mathrm{Fmoc}_{-} \mathrm{VE}_{2}$ led to a significant quenching of the fluorescence in a dose-dependent manner. Fig. 4B shows the DOX fluorescence intensity at $595 \mathrm{~nm}$ before and after incorporation into $\mathrm{PEG}_{5 \mathrm{~K}^{-}}$ Fmoc-VE 2 . Likewise, $\mathrm{PEG}_{5 \mathrm{~K}}-\mathrm{Fmoc}-\mathrm{VE}_{2}$ caused the quenching of DOX fluorescence in a dose-dependent manner. The quenching of either Fmoc or DOX fluorescence is likely due to the energy transfer triggered by the intermolecular $\pi-\pi$ stacking interaction between the Fmoc motif and the aromatic rings of DOX.

We also noticed a fluorescence emission at $300 \mathrm{~nm}$ from $\mathrm{PEG}_{5 \mathrm{~K}}-\mathrm{VE}_{2}$ (Fig. 4A). This is likely attributed to the benzene ring in Vitamin $\mathrm{E}$ as no fluorescence emission was detected at this wavelength from a similar conjugate of PEG with two molecules of oleic acid (data not shown). Similarly, $\mathrm{PEG}_{5 \mathrm{~K}}-\mathrm{VE}_{2}$ and DOX caused the quenching of the other's fluorescence in a dose-dependent manner (Fig. 4A \& B), suggesting that the benzene ring in Vitamin $\mathrm{E}$ is also involved in the carrier/DOX $\pi-\pi$ stacking interaction, albeit to a lesser extent.

Fig. $4 \mathrm{C}$ shows the UV-absorbance of free DOX and DOX formulated in $\mathrm{PEG}_{5 \mathrm{~K}}-\mathrm{VE}_{2}$ or $\mathrm{PEG}_{5 \mathrm{~K}}-\mathrm{Fmoc}_{\mathrm{V}} \mathrm{VE}_{2}$ micelles. A clear red shift of DOX UV-absorbance was detected in both micellar formulations, particularly in $\mathrm{PEG}_{5 \mathrm{~K}}-\mathrm{Fmoc}-\mathrm{VE}_{2} / \mathrm{DOX}$ mixed micelles, further supporting the notion that $\pi-\pi$ stacking contributed to the carrier/DOX interactions. 
In addition to hydrophobic interaction and $\pi-\pi$ stacking, hydrogen bonding is likely to be involved in the carrier $\left(\mathrm{PEG}_{5 \mathrm{~K}}-\mathrm{VE}_{2}\right.$ or $\left.\mathrm{PEG}_{5 \mathrm{~K}}-\mathrm{Fmoc}-\mathrm{VE}_{2}\right) / \mathrm{DOX}$ interaction. The carbamate group in Fmoc, the amide bond in lysine, as well as the ester linkage in between Vitamin $\mathrm{E}$ and lysine could interact with the hydroxyl groups in DOX through hydrogen bonding. To test this hypothesis, FT-IR was employed to compare the hydrogen bonding in DOX-loaded micelles and that in carrier alone. As shown in Fig. 5B, after subtracting the IR of $\mathrm{PEG}_{5 \mathrm{~K}^{-}}$ Fmoc-VE 2 from that of $\mathrm{PEG}_{5 \mathrm{~K}}-\mathrm{Fmoc}-\mathrm{VE}_{2} / \mathrm{DOX}$, two peaks at $1637.1 \mathrm{~cm}^{-1}$ and 1754.3 $\mathrm{cm}^{-1}$ were detected. The reduction of absorbance at $1754.3 \mathrm{~cm}^{-1}$ and a simultaneous increase of absorbance at $1637.1 \mathrm{~cm}^{-1}$ suggest that incorporation of DOX led to disruption of the hydrogen bonding among carrier molecules themselves and, at the same time, the formation of new hydrogen bonding between carrier and DOX molecules. Similar results were found for $\mathrm{PEG}_{5 \mathrm{~K}}-\mathrm{VE}_{2}$ micellar system (Fig. 5D).

\section{Evaluation of the hemolytic activity of $P E G_{5 K}-F m o c-V E_{2}$}

As an intravenous formulation, the potential hemolytic activity of $\mathrm{PEG}_{5 \mathrm{~K}}-\mathrm{Fmoc}_{-} \mathrm{VE}_{2}$ micellar formulation needs to be addressed. Fig. 6 shows the result of a hemolysis assay. PEI, a cationic polymer with potent cell surface activity, was included as a positive control. Treatment with PEI led to significant hemolysis in a dose-dependent manner. At a concentration of $1 \mathrm{mg} / \mathrm{mL}$, almost all of the red blood cells were lysed by PEI. In contrast, only negligible level of hemolysis was observed for $\mathrm{PEG}_{5 \mathrm{~K}}-\mathrm{Fmoc}_{-} \mathrm{VE}_{2}$ even at the concentration of $1 \mathrm{mg} / \mathrm{mL}$. The very low level of hemolytic effect of $\mathrm{PEG}_{5 \mathrm{~K}}-\mathrm{Fmoc}-\mathrm{VE}_{2}$ indicates that $\mathrm{PEG}_{5 \mathrm{~K}}-\mathrm{Fmoc}-\mathrm{VE}_{2}$ is a mild surfactant that can be safely administered intravenously.

\section{In vitro cytotoxicity}

Fig. 7 shows the cytotoxic effect of different DOX formulations on murine breast cancer cells, 4T1.2. Cells were challenged by DOX, Doxil, $\mathrm{PEG}_{5 \mathrm{~K}}-\mathrm{VE}_{2} / \mathrm{DOX}$ and $\mathrm{PEG}_{5 \mathrm{~K}}-\mathrm{Fmoc}-$ $\mathrm{VE}_{2} / \mathrm{DOX}$ at various concentrations of DOX, and the cytotoxicity was determined by MTT assay $72 \mathrm{~h}$ later. A time- and concentration-dependent cell-killing effect was shown for all DOX formulations in $4 \mathrm{~T} 1.2$ cells. The $\mathrm{IC}_{50}$ was $186.70,253.83,89.21$, and $77.57 \mathrm{ng} / \mathrm{mL}$ for DOX, Doxil, $\mathrm{PEG}_{5 \mathrm{~K}}-\mathrm{VE}_{2} / \mathrm{DOX}$, and $\mathrm{PEG}_{5 \mathrm{~K}}-\mathrm{Fmoc}_{-} \mathrm{VE}_{2} / \mathrm{DOX}$, respectively. The higher levels of cytotoxicity for the two micellar DOX formulations were likely due to an increased cellular uptake of DOX and effective release following intracellular delivery (Fig. 7). Doxil was slightly less active than free DOX, which is likely due to the ineffective release of DOX from the liposomes following intracellular delivery [33].

\section{Reversal of multidrug resistance}

Drug resistance is one of the major factors involved in the failure of chemotherapy [34]. Various mechanisms have been identified that are involved in the different types and/or stages of cancers [35,36]. One major mechanism involves the overexpression of $\mathrm{P}$ glycoprotein (P-gp), which plays an important role in developing multiple drug resistance (MDR) [37]. P-gp, a member of ATP-binding cassette transporter, is one of the major drug efflux transporters and increased expression of P-gp leads to decreased drug accumulation in multidrug-resistant cells, and the development of resistance to anticancer drugs [38]. NCI/ ADR-RES is a drug-resistant cell line that involves the overexpression of P-gp [39]. Thus, 
following the evaluation of cytotoxicity of the different DOX formulations in 4T1.2 cells, their cytotoxicity was further examined in NCI/ADR-RES cells. As shown in Fig. 8, the overall antiproliferative effects of all DOX formulations were significantly reduced in NCI/ ADR-RES cells compared to drug-sensitive cell line, 4T1.2 cells. This is somewhat expected considering the drug resistant nature of NCI/ADR-RES cells. It is also apparent that $\mathrm{PEG}_{5 \mathrm{~K}^{-}}$ Fmoc- $\mathrm{VE}_{2} / \mathrm{DOX}$ exhibited a higher level of cytotoxicity than the remaining DOX formulations in NCI/ADR-RES cells (Fig. 8). More importantly, $\mathrm{PEG}_{5 \mathrm{~K}}-\mathrm{Fmoc}_{-\mathrm{VE}} / \mathrm{DOX}$ was 5.6-times as effective as free DOX in NCI/ADR-RES cells, which represents a more dramatic improvement of cytotoxicity over free DOX compared to that (2.4-times) in 4T1.2 cells. It is also worth noting that Doxil was more active than free DOX in NCI/ADR-RES cells, which is in contrast to what was shown in 4T1.2 cells. These data suggested that both $\mathrm{PEG}_{5 \mathrm{~K}}-\mathrm{Fmoc}-\mathrm{VE}_{2}$ and Doxil formulations were capable of partially reversing the drug resistance in NCI/ADR-RES cells.

To examine whether the improved cytotoxicity of DOX-loaded $\mathrm{PEG}_{5 \mathrm{~K}}-\mathrm{Fmoc}-\mathrm{VE}_{2}$ was due to the enhanced intracellular delivery of DOX, DOX uptake was evaluated in NCI/ADRRES cells following treatment of different DOX formulations. Fig. 9A shows the fluorescence images of cells $1 \mathrm{~h}$ following the different treatments. Least amounts of fluorescence signals were observed in the cells treated with free DOX, which could be attributed to the free accessibility of DOX by P-gp efflux transporter that is overexpressed in NCI/ADR-RES cells. Cells treated with Doxil showed increased fluorescence signals compared to free DOX group. This was consistent with the report that liposomal DOX was able to bypass the drug transport in MDR cells [40]. It is also apparent that cells treated with $\mathrm{PEG}_{5 \mathrm{~K}}-\mathrm{Fmoc}_{-} \mathrm{VE}_{2} / \mathrm{DOX}$ showed the strongest fluorescence signals. Similar results were shown in cells treated with different DOX formulation for $3 \mathrm{~h}$ (Fig. 9B). The DOX uptake efficiency was further quantified by flow cytometry (Fig. 9C \& 9D). The data were consistent with what was found in confocal imaging. Cells treated with $\mathrm{PEG}_{5 \mathrm{~K}}-\mathrm{Fmoc}-$ $\mathrm{VE}_{2} / \mathrm{DOX}$ provided the highest level of cell-associated fluorescence signals. Endocytosis is likely to be involved in the cellular uptake of micellar DOX as punctuated distribution was visualized for both micellar formulations. More studies will be conducted in the future to further elucidate the mechanism of cellular uptake of $\mathrm{PEG}_{5 \mathrm{~K}}-\mathrm{Fmoc}-\mathrm{VE}_{2} / \mathrm{DOX}$.

The more effective DOX accumulation in cells treated with $\mathrm{PEG}_{5 \mathrm{~K}}-\mathrm{Fmoc}-\mathrm{VE}_{2} / \mathrm{DOX}$ is likely attributed to the stable mixed micelles as a result of strong carrier/DOX interaction as discussed earlier. This will minimize the release of DOX from the micelles before they are taken up by the tumor cells. On the other hand, $\mathrm{PEG}_{5 \mathrm{~K}}-\mathrm{Fmoc}-\mathrm{VE}_{2}$ may facilitate the intracellular accumulation of DOX via inhibiting the function of P-gp. TPGS $1 \mathrm{~K}$ is a wellknown inhibitor of P-gp via directly inhibiting the activity of P-gp ATPase. We hypothesized that $\mathrm{PEG}_{5 \mathrm{~K}}-\mathrm{Fmoc}-\mathrm{VE}_{2}$ shall possess a similar biological activity considering the structural similarity between TPGS and $\mathrm{PEG}_{5 \mathrm{~K}}-\mathrm{Fmoc}-\mathrm{VE}_{2}$. To test this hypothesis, the effect of $\mathrm{PEG}_{5 \mathrm{~K}}-\mathrm{Fmoc}-\mathrm{VE}_{2}$ on P-gp activity was evaluated via examining its impact on verapamil-stimulated P-gp ATPase activity (Fig. 10). TPGS ${ }_{1 \mathrm{k}}$ was utilized as a positive control. $\triangle \mathrm{RLU}$ represents the consumption of ATP in the system. As expected, TPGS $\mathrm{S}_{1 \mathrm{k}}$ treatment led to a decrease of $\triangle \mathrm{RLU}$ in a dose-dependent fashion. Importantly, $\mathrm{PEG}_{5 \mathrm{~K}^{-}}$ Fmoc- $\mathrm{VE}_{2}$ showed a level of inhibition on P-gp ATPase activity that was comparable to that of TPGS ${ }_{1 K}$. The mechanism for the inhibition of P-gp ATPase by $P G_{5 K}-F m o c-V E_{2}$ is not 
clearly understood at present. $\mathrm{PEG}_{5 \mathrm{~K}}-\mathrm{Fmoc}-\mathrm{VE}_{2}$ may be a substrate for ATPase and compete directly with other substrates for the binding to ATPase. In addition, $\mathrm{PEG}_{5 \mathrm{~K}}-\mathrm{Fmoc}$ $\mathrm{VE}_{2}$ may bind to the ATPase-substrate complex, limiting the effectiveness of ATPase to hydrolyze ATP. More studies are underway to fully unveil the details on how $\mathrm{PEG}_{5 \mathrm{~K}}-\mathrm{Fmoc}_{\text {- }}$ $\mathrm{VE}_{2}$ inhibits P-gp ATPase activity. It should be noted that, in addition to DOX, there are many other potent chemotherapeutics that are the substrates of P-gp, such as camptothecin and paclitaxel. Therefore, $\mathrm{PEG}_{5 \mathrm{~K}}-\mathrm{Fmoc}_{-} \mathrm{VE}_{2}$ may hold a promise to improve the effectiveness of these therapeutic agents as well.

\section{Near infrared fluorescence imaging}

The ability of $\mathrm{PEG}_{5 \mathrm{~K}}-\mathrm{Fmoc}-\mathrm{VE}_{2}$ for targeting tumors was investigated in nude mice bearing PC-3 xenograft, using a hydrophobic near infrared fluorescence (NIRF) dye, DiD. Two hundred $\mu \mathrm{L}$ of $\mathrm{PEG}_{5 \mathrm{~K}}-\mathrm{Fmoc}-\mathrm{VE}_{2}$ nanoparticles containing DiD was intravenously injected into a mouse bearing bilateral PC-3 tumors. Fluorescence signals were observed in tumor areas as early as $6 \mathrm{~h}$ post-injection, which peaked around $24 \mathrm{~h}$ and retained at a significant level for $96 \mathrm{~h}$ (Fig. 11A). Following the last imaging at $96 \mathrm{~h}$ post-injection, mice were sacrificed and tumors and major organs were excised, imaged and quantified using a Carestream Molecular Imaging System (Fig. 11B). Intense fluorescence signals were observed in tumors for DiD-loaded $\mathrm{PEG}_{5 \mathrm{~K}}-\mathrm{Fmoc}-\mathrm{VE}_{2}$. Moderate levels of fluorescence signals were also discerned in liver and lungs, which was due to the nonspecific clearance of foreign particles via the RES. Fig. 11C showed the quantified fluorescence intensity for different organs, which was consistent with the observation in Fig. 11B. The effective tumor accumulation of $\mathrm{PEG}_{5 \mathrm{~K}}-\mathrm{Fmoc}-\mathrm{VE}_{2} / \mathrm{DiD}$ could be ascribed to its excellent stability endowed by the strong carrier/DiD and carrier/carrier interactions. PEG on the surface of the carrier can also provide shielding effect against opsonins. Furthermore, the very small sizes of $\mathrm{PEG}_{5 \mathrm{~K}}-\mathrm{Fmoc}-\mathrm{VE}_{2} / \mathrm{DiD}$ nanoparticles shall facilitate the extravasation and deep penetration into the tumor tissues $[41,42]$.

\section{In vivo DOX pharmacokinetics and biodistribution}

The DOX blood kinetics as a function of time following i.v. bolus administration of DOX, DOX-loaded $\mathrm{PEG}_{5 \mathrm{~K}}-\mathrm{VE}_{2}$ and DOX-loaded $\mathrm{PEG}_{5 \mathrm{~K}}-\mathrm{Fmoc}-\mathrm{VE}_{2}$ was illustrated in Fig. 12A. It is apparent that the DOX-loaded $\mathrm{PEG}_{5 \mathrm{~K}}-\mathrm{Fmoc}-\mathrm{VE}_{2}$ showed the highest level of DOX retention in circulation in comparison to free DOX and DOX-loaded $\mathrm{PEG}_{5 \mathrm{~K}}-\mathrm{VE}_{2}$. Meanwhile, the pharmacokinetic parameters, obtained by fitting the data to a noncompartment model, were outlined in Tab. 2. Incorporation of DOX into $\mathrm{PEG}_{5 \mathrm{~K}}-\mathrm{VE}_{2}$ micelles resulted in a significantly greater $\mathrm{t}_{1 / 2}, \mathrm{AUC}$, and $\mathrm{C}_{\max }$ over free DOX. However, these parameters were further improved in DOX-loaded $\mathrm{PEG}_{5 \mathrm{~K}}-\mathrm{Fmoc}-\mathrm{VE}_{2}$ nanomicelles.

The $\mathrm{t}_{1 / 2}$, AUC, and $\mathrm{C}_{\max }$ of DOX in $\mathrm{PEG}_{5 \mathrm{~K}}-\mathrm{Fmoc}-\mathrm{VE}_{2} / \mathrm{DOX}$ were 3.62, 18.22, and 6.59folds higher, respectively, than those of free DOX. In contrast, $\mathrm{V}_{d}$ and $\mathrm{CL}$ for $\mathrm{PEG}_{5 \mathrm{~K}}-\mathrm{Fmoc}-$ $\mathrm{VE}_{2} / \mathrm{DOX}$ were significantly lower than those for free DOX and $\mathrm{PEG}_{5 \mathrm{~K}}-\mathrm{VE}_{2} / \mathrm{DOX}$. Taken together, these data demonstrated that DOX formulated in $\mathrm{PEG}_{5 \mathrm{~K}}-\mathrm{Fmoc}-\mathrm{VE}_{2}$ micelles was able to circulate for a significantly longer period of time in blood. 
Next we went on to investigate whether our $\mathrm{PEG}_{5 \mathrm{~K}}-\mathrm{Fmoc}-\mathrm{VE}_{2} / \mathrm{DOX}$ formulation can improve the DOX biodistribution profile in tumor-bearing mice. Different DOX formulations were i.v. administered to 4T1.2 tumor-bearing mice at a DOX dosage of 5 $\mathrm{mg} / \mathrm{kg}$. Twenty-four $\mathrm{h}$ following the injection, blood, tumors, and major organs were collected for the quantification of DOX. Compared to free DOX, there were significantly greater amounts of DOX accumulated in tumors for both types of DOX nanomicelles (Fig. 12B), which was attributed to the EPR effect of micellar formulations. We also noticed that DOX formulated in $\mathrm{PEG}_{5 \mathrm{~K}}-\mathrm{Fmoc}-\mathrm{VE}_{2}$ micelles was more effective in tumor accumulation compared to the counterpart without Fmoc motif (Fig. 12B). This is likely attributed to a better stability of $\mathrm{PEG}_{5 \mathrm{~K}}-\mathrm{Fmoc}-\mathrm{VE}_{2} / \mathrm{DOX}$ mixed micelles in the blood due to the enhanced carrier/drug interaction as discussed before. In addition, the presence of Fmoc may help improve the carrier stability via imposing steric hindrance against the degrading enzymes in the blood. Indeed, $\mathrm{PEG}_{5 \mathrm{~K}}-\mathrm{Fmoc}-\mathrm{VE}_{2}$ is less sensitive to esterase-mediated cleavage than the counterpart without an Fmoc motif (Fig. S10) in an in vitro study. The improved stability of $\mathrm{PEG}_{5 \mathrm{~K}}-\mathrm{Fmoc}_{-} \mathrm{VE}_{2} / \mathrm{DOX}$ mixed micelles may contribute significantly to a longer $\mathrm{t}_{1 / 2}$ in the blood (Tab. 2) and thus increased chance for passive accumulation at tumor tissues via EPR effect.

Relatively high levels of DOX uptake were also observed in liver and lung, which was due to the nonspecific uptake of particles by these tissues. Importantly, heart distribution of DOX was significantly reduced in $\mathrm{PEG}_{5 \mathrm{~K}}-\mathrm{Fmoc}_{-} \mathrm{VE}_{2} / \mathrm{DOX}$ compared with free $\mathrm{DOX}$ and $\mathrm{PEG}_{5 \mathrm{~K}}-\mathrm{VE}_{2} / \mathrm{DOX}$. This is significant considering that cardiotoxicity is a major adverse effect associated with the application of DOX in clinic. This will allow higher dose of DOX to be used to maximize the therapeutic effect.

\section{Maximum tolerated dose (MTD)}

To examine whether the significantly improved stability of $\mathrm{PEG}_{5 \mathrm{~K}}-\mathrm{Fmoc}-\mathrm{VE}_{2} / \mathrm{DOX}$ will lead to reduced systemic toxicity in vivo, MTD of various DOX formulations was assessed in tumor-free mice. Mice were treated with i.v. bolus injection of different doses of free DOX, $\mathrm{PEG}_{5 \mathrm{~K}}-\mathrm{VE}_{2} / \mathrm{DOX}$ and $\mathrm{PEG}_{5 \mathrm{~K}}-\mathrm{Fmoc}-\mathrm{VE}_{2} / \mathrm{DOX}$ followed by observation of changes in body weight and other general signs of toxicity. As shown in Tab. 3, no significant toxicity was noticed for free DOX group at a dosage of $10 \mathrm{mg}$ DOX $/ \mathrm{kg}$. Increasing the dosage to $15 \mathrm{mg} / \mathrm{kg}$ led to the death of 2 out of 3 treated mice. Therefore, the MTD for free DOX at a single injection was around $10 \mathrm{mg} / \mathrm{kg}$, which was consistent with the literature [43]. $\mathrm{PEG}_{5 \mathrm{~K}}-\mathrm{VE}_{2} / \mathrm{DOX}$ was well tolerated at a dosage of $20 \mathrm{mg} / \mathrm{kg}$ : no significant changes were observed in the general appearance or activity other than $6.2 \%$ weight loss. Increasing the DOX dose to $30 \mathrm{mg} / \mathrm{kg}$ resulted in the death of all 3 treated mice, suggesting that the single i.v. MTD for DOX-loaded $\mathrm{PEG}_{5 \mathrm{~K}}-\mathrm{VE}_{2}$ micelles was around $20 \mathrm{mg} \mathrm{DOX} / \mathrm{kg}$, which was a 2 -fold increase over free DOX. $\mathrm{PEG}_{5 \mathrm{~K}}-\mathrm{Fmoc}-\mathrm{VE}_{2} / \mathrm{DOX}$ showed a lowest level of toxicity with a MTD around $30 \mathrm{mg} / \mathrm{kg}$, which was 3-fold and 1.5-fold increase over free DOX and $\mathrm{PEG}_{5 \mathrm{~K}^{-}} \mathrm{VE}_{2} / \mathrm{DOX}$, respectively. The improved MTD of DOX-loaded $\mathrm{PEG}_{5 \mathrm{~K}^{-}}$ Fmoc- $\mathrm{VE}_{2}$ is likely attributed to a slower and sustained DOX release kinetics (Fig. 3) due to the enhanced stability, which will liberate its payload gradually instead of a bursting release; as such, the toxicity will be better tolerated. In addition, it has been shown that Vitamin E and Fmoc both have anti-inflammatory activities which may also contribute to the reduced 
toxicity of $\mathrm{PEG}_{5 \mathrm{~K}}-\mathrm{Fmoc}_{-} \mathrm{VE}_{2} / \mathrm{DOX}$ [44-46]. More studies are still needed to fully elucidate the underlying mechanisms for the reduced toxicity of $\mathrm{PEG}_{5 \mathrm{~K}}-\mathrm{Fmoc}-\mathrm{VE}_{2} / \mathrm{DOX}$.

\section{In vivo anti-tumor efficacy}

Both drug-sensitive (4T1.2 and PC-3) and drug-resistant (KB 8-5) tumor models were employed to evaluate the in vivo anti-tumor activity of DOX-loaded $\mathrm{PEG}_{5 \mathrm{~K}}-\mathrm{Fmoc}-\mathrm{VE}_{2}$. 4T1.2 is an aggressive syngeneic murine breast cancer model. As depicted in Fig. 13A, a rapid and unrestrained growth of tumors was observed in mice treated with saline and mice had to be sacrificed early due to the development of severe ulceration. After three consecutive injections, all of the mice treated with free DOX died from systemic toxicity on day 7. PEGylated liposomal DOX (Doxil) was well tolerated and showed a moderate level of activity in delaying the tumor growth, which is consistent with previous reports [40, 4750]. It is also apparent that incorporation of Fmoc motif into $\mathrm{PEG}_{5 \mathrm{~K}}-\mathrm{VE}_{2} / \mathrm{DOX}$ led to a significant improvement in antitumor activity. The IRs were $82.63,67.73$, and $62.24 \%$ for $\mathrm{PEG}_{5 \mathrm{~K}}-\mathrm{Fmoc}-\mathrm{VE}_{2} / \mathrm{DOX}, \mathrm{PEG}_{5 \mathrm{~K}}-\mathrm{VE}_{2} / \mathrm{DOX}$, and Doxil, respectively (Tab. 4). In addition, increasing DOX dosage to $20 \mathrm{mg} / \mathrm{kg}$ resulted in further enhancement in the antitumor activity of DOX-loaded $\mathrm{PEG}_{5 \mathrm{~K}}-\mathrm{Fmoc}-\mathrm{VE}_{2}$ micelles. No obvious toxicity was noticed at both dosages (Fig. 13B).

The improved performance of the two micellar formulations $\left(\mathrm{PEG}_{5 \mathrm{~K}^{-}} \mathrm{VE}_{2}\right.$ and $\mathrm{PEG}_{5 \mathrm{~K}^{-}}$ Fmoc- $\mathrm{VE}_{2}$ ) over Doxil in inhibiting the tumor growth may be attributed to their more effective accumulation at tumors based on their relatively small size ( $\sim 20 \mathrm{~nm}$ and $\sim 60 \mathrm{~nm}$ for $\mathrm{PEG}_{5 \mathrm{~K}}-\mathrm{VE}_{2} / \mathrm{DOX}$ and $\mathrm{PEG}_{5 \mathrm{~K}}-\mathrm{Fmoc}-\mathrm{VE}_{2} / \mathrm{DOX}$, respectively). It has been generally regarded that a drug carrier needs to have a size range of $\sim 200 \mathrm{~nm}$ in order to capitalize on the EPR effect. However, recent studies have shown that sub-100 $\mathrm{nm}$ is required for particles to effectively penetrate the tumor tissues, particularly poorly vascularized tumors $[41,42]$. The size advantage of the two micellar DOX formulations over Doxil $(\sim 100 \mathrm{~nm})$ may contribute to their enhanced antitumor activity. In addition, the carriers may contribute to the overall antitumor activity via delaying or reversing the drug resistance through inhibiting the activity of P-gp. The further improved performance of $\mathrm{PEG}_{5 \mathrm{~K}}-\mathrm{Fmoc}-\mathrm{VE}_{2}$ over $\mathrm{PEG}_{5 \mathrm{~K}}-\mathrm{VE}_{2}$ is likely due to the more effective drug/carrier interaction as well as the interaction among the carrier molecules themselves, leading to improved formulation stability and more effective DOX delivery to tumors (Fig. 12).

After demonstrating effective inhibition of tumor growth in the syngeneic murine breast cancer model, the therapeutic effect of DOX-loaded $\mathrm{PEG}_{5 \mathrm{~K}}-\mathrm{Fmoc}-\mathrm{VE}_{2}$ micelles was further examined in nude mice bearing human prostate cancer xenograft (PC-3) (Fig. 14). In this study, a lower DOX dosage $(5 \mathrm{mg} / \mathrm{kg}$ ) was used to avoid the death of animals in free DOX group, which allowed the comparison of all treatment groups over a relatively long period of time. Similarly, $\mathrm{PEG}_{5 \mathrm{~K}}-\mathrm{Fmoc}-\mathrm{VE}_{2} / \mathrm{DOX}$ gave the highest level of tumor growth inhibition among all DOX formulations examined. Doubling the DOX dosage to $10 \mathrm{mg} / \mathrm{kg}$ led to a further improvement of the antitumor efficacy (Fig. 14A). Tab. 5 shows the IR of different DOX formulations on day 19. Mice in both saline and free DOX groups showed significant loss of body weight after day 19 (Fig. 14B), which was likely attributed to the cachexia that 
is caused by the overgrowth of tumor. No significant changes were noticed in other treatment groups in either body weight (Fig. 14B) or the general appearance.

Fig. 15 shows the in vivo antitumor activity of DOX-loaded $\mathrm{PEG}_{5 \mathrm{~K}}-\mathrm{Fmoc}-\mathrm{VE}_{2}$ micelles in a drug-resistant tumor model, KB 8-5. At a dosage of $5 \mathrm{mg} / \mathrm{kg}$, free DOX barely showed any effect in inhibiting the tumor growth. Increasing the dose to $7.5 \mathrm{mg} / \mathrm{kg}$ only led to a slight improvement in antitumor activity. These are in consistence with the drug-resistant nature of this tumor model [51]. In contrast, incorporation of DOX into $\mathrm{PEG}_{5 \mathrm{~K}}-\mathrm{VE}_{2}$ led to a significant improvement in antitumor activity: $\mathrm{PEG}_{5 \mathrm{~K}}-\mathrm{VE}_{2} / \mathrm{DOX}$ at $5 \mathrm{mg} / \mathrm{kg}$ was even more effective than free DOX at $7.5 \mathrm{mg} / \mathrm{kg}$. In agreement with studies in other tumor models (Figs. 13 and 14), $\mathrm{PEG}_{5 \mathrm{~K}}-\mathrm{Fmoc}_{-\mathrm{VE}_{2}} / \mathrm{DOX}$ was even more effective than $\mathrm{PEG}_{5 \mathrm{~K}}-\mathrm{VE}_{2} / \mathrm{DOX}$ in inhibiting the tumor growth at a same dosage $(5 \mathrm{mg} / \mathrm{kg})$. Increasing the dose to $7.5 \mathrm{mg} / \mathrm{kg}$ led to almost complete inhibition of tumor growth with an IR of $89.21 \%$ (Fig. 15 and Tab. 6). Both micellar formulations were well tolerated. In contrast, significant weight loss was observed in free DOX-treated mice at both dosages (Fig. 15B). Data from Fig. 15 strongly suggest that our improved formulation is capable of reversing the drug-resistance, at least partially, although more studies are needed to better understand the underlying mechanism.

\section{Conclusions}

Incorporation of an Fmoc motif at the interfacial region of $\mathrm{PEG}_{5 \mathrm{~K}}-\mathrm{VE}_{2}$ led to significant improvement of the system through the introduction of an additional mechanism of drug/ carrier interaction. Doxorubicin (DOX) could be effectively loaded into $\mathrm{PEG}_{5 \mathrm{~K}}-\mathrm{Fmoc}-\mathrm{VE}_{2}$ micelles at a DLC of $39.9 \%$, which compares favorably to most reported DOX nanoformulations. $\mathrm{PEG}_{5 \mathrm{~K}}-\mathrm{Fmoc}-\mathrm{VE}_{2} / \mathrm{DOX}$ exerted significantly higher levels of cytotoxicity over DOX, Doxil as well as $\mathrm{PEG}_{5 \mathrm{~K}}-\mathrm{VE}_{2} / \mathrm{DOX}$ in $4 \mathrm{~T} 1.2$ cells and demonstrated a potential to reverse the DOX resistance in NCI/ADR-RES cells. PK and biodistribution studies showed an increased half-life in blood circulation and more effective tumor accumulation for DOX formulated in $\mathrm{PEG}_{5 \mathrm{~K}}-\mathrm{Fmoc}_{-} \mathrm{VE}_{2}$ micelles. More importantly, DOXloaded $\mathrm{PEG}_{5 \mathrm{~K}}-\mathrm{Fmoc}-\mathrm{VE}_{2}$ micelles showed an excellent safety profile with a MTD ( $\sim 30 \mathrm{mg}$ $\mathrm{DOX} / \mathrm{kg}$ ) that is about 3 times as much as that for free DOX. Finally, superior antitumor activity was demonstrated for $\mathrm{PEG}_{5 \mathrm{~K}}-\mathrm{Fmoc}-\mathrm{VE}_{2} / \mathrm{DOX}$ in both drug-sensitive (4T1.2 and PC-3) and drug-resistant (KB 8-5) tumor models.

\section{Supplementary Material}

Refer to Web version on PubMed Central for supplementary material.

\section{Acknowledgments}

This work was supported in part by NIH grants RO1CA174305, RO1GM102989, and R21CA173887. We would like to thank Dr. Robert Gibbs for critical reading of this manuscript.

\section{References}

1. Tacar O, Sriamornsak P, Dass CR. Doxorubicin: an update on anticancer molecular action, toxicity and novel drug delivery systems. J Pharm Pharmacol. 2013; 65:157-170. [PubMed: 23278683] 
2. Fornari FA, Randolph JK, Yalowich JC, Ritke MK, Gewirtz DA. Interference by doxorubicin with DNA unwinding in MCF-7 breast tumor cells. Mol Pharmacol. 1994; 45:649- 656. [PubMed: 8183243]

3. Momparler RL, Karon M, Siegel SE, Avila F. Effect of adriamycin on DNA, RNA, and protein synthesis in cell-free systems and intact cells. Cancer Res. 1976; 36:2891-2895. [PubMed: 1277199]

4. Pommier Y, Leo E, Zhang H, Marchand C. DNA topoisomerases and their poisoning by anticancer and antibacterial drugs. Chem Biol. 2010; 17:421-433. [PubMed: 20534341]

5. Takemura G, Fujiwara H. Doxorubicin-induced cardiomyopathy from the cardiotoxic mechanisms to management. Prog Cardiovasc Dis. 2007; 49:330-352. [PubMed: 17329180]

6. Minotti G, Menna P, Salvatorelli E, Cairo G, Gianni L. Anthracyclines: molecular advances and pharmacologic developments in antitumor activity and cardiotoxicity. Pharmacol Rev. 2004; 56:185-229. [PubMed: 15169927]

7. Mi Y, Liu Y, Feng SS. Formulation of docetaxel by folic acid-conjugated D-a-tocopheryl polyethylene glycol succinate 2000 (Vitamin E TPGS2k) micelles for targeted and synergistic chemotherapy. Biomaterials. 2011; 32:4058-4066. [PubMed: 21396707]

8. Win KY, Feng SS. In vitro and in vivo studies on vitamin E TPGS-emulsified poly(D,L-lactic-coglycolic acid)nanoparticles for paclitaxel formulation. Biomaterials. 2006; 27:2285-2291. [PubMed: 16313953]

9. Ma Y, Zheng Y, Liu K, Tian G, Tian Y, Xu L, et al. Nanoparticles of poly(lactide-co-glycolide)-da-tocopheryl polyethylene glycol 1000 succinate random copolymer for cancer treatment. Nanoscale Res Lett. 2010; 6:1161-1169. [PubMed: 20596457]

10. Wang J, Sun J, Chen Q, Gao Y, Li L, Li H, et al. Star-shape copolymer of lysine-linked ditocopherol polyethylene glycol 2000 succinate for doxorubicin delivery with reversal of multidrug resistance. Biomaterials. 2012; 28:6877-6888. [PubMed: 22770799]

11. Muthu MS, Kulkarni SA, Xiong J, Feng SS. Vitamin E TPGS coated liposomes enhanced cellular uptake and cytotoxicity of docetaxel in brain cancer cells. Int J Pharm. 2011; 421:332-340. [PubMed: 22001537]

12. Cao N, Feng SS. Doxorubicin conjugated to D-alpha-tocopheryl polyethylene glycol 1000 succinate (TPGS): conjugation chemistry, characterization, in vitro and in vivo evaluation. Biomaterials. 2008; 29:3856-3865. [PubMed: 18606445]

13. Anbharasi V, Cao N, Feng SS. Doxorubicin conjugated to D-alpha-tocopheryl polyethylene glycol succinate and folic acid as a prodrug for targeted chemotherapy. J Biomed Mater Res A. 2010; 94:730-743. [PubMed: 20225211]

14. Yu L, Bridgers A, Polli J, Vickers A, Long S, Roy A, et al. Vitamin E-TPGS increases absorption flux of an HIV protease inhibitor by enhancing its solubility and permeability. Pharm Res. 1999; 16:1812-1817. [PubMed: 10644067]

15. Dintaman JM, Silverman JA. Inhibition of P-glycoprotein by D-alpha-tocopheryl polyethylene glycol 1000 succinate (TPGS). Pharm Res. 1999; 16:1550-1556. [PubMed: 10554096]

16. Varma MVS, Panchagnula R. Enhanced oral paclitaxel absorption with vitamin E-TPGS: effect on solubility and permeability in vitro, in situ and in vivo. Eur J Pharm Sci. 2005; 25:445-453. [PubMed: 15890503]

17. Collnot EM, Baldes C, Schaefer UF, Edgar KJ, Wempe MF, Lehr CM. Vitamin E TPGS pglycoprotein inhibition mechanism: influence on conformational flexibility, intracellular ATP levels, and role of time and site of access. Mol Pharm. 2010; 7:642-651. [PubMed: 20205474]

18. Constantinides PP, Han JH, Davis SS. Advances in the use of tocols as drug delivery vehicles. Pharm Res. 2006; 23:243-255. [PubMed: 16421666]

19. Huang Y, Lu J, Gao X, Li J, Zhao W, Sun M, et al. PEG-derivatized embelin as a dual functional carrier for the delivery of paclitaxel. Bioconjug Chem. 2012; 23:1443-1451. [PubMed: 22681537]

20. Lu J, Huang Y, Zhao W, Marquez RT, Meng X, Li J, et al. PEG-Derivatized Embelin as a Nanomicellar Carrier for Delivery of Paclitaxel to Breast and Prostate Cancers. Biomaterials. 2013; 34:1591-1600. [PubMed: 23182923] 
21. Zhang X, Lu J, Huang Y, Zhao W, Chen Y, Li J, et al. PEG-farnesylthiosalicylate conjugate as a nanomicellar carrier for delivery of paclitaxel. Bioconjug Chem. 2013; 24:464-472. [PubMed: 23425093]

22. Chen Y, Zhang X, Lu J, Huang Y, Li J, Li S. Targeted Delivery of Curcumin to Tumors via PEGDerivatized FTS-Based Micellar System. AAPS J. 2014; 16:600-608. [PubMed: 24706375]

23. Kim JY, Kim S, Papp M, Park K, Pinal R. Hydrotropic solubilization of poorly water-soluble drugs. J Phar Sci. 2010; 99:3953-3965.

24. Kim JY, Kim S, Pinal R, Park K. Hydrotropic polymer micelles as versatile vehicles for delivery of poorly water-soluble drugs. J Control Release. 2011; 152:13-20. [PubMed: 21352878]

25. Gao X, Huang Y, Makhov AM, Epperly M, Lu J, Grab S, et al. Nanoassembly of surfactants with interfacial drug-interactive motifs as tailor-designed drug carriers. Mol Pharm. 2013; 10:187-98. [PubMed: 23244299]

26. Zhang P, Lu J, Huang Y, Zhao W, Zhang Y, Zhang X, et al. Design and evaluation of a PEGylated lipopeptide equipped with drug-interactive motifs as an improved drug carrier. AAPS J. 2014; 16:114-124. [PubMed: 24281690]

27. Lu J, Huang Y, Zhao W, Chen Y, Li J, Gao X, et al. Design and characterization of PEGderivatized vitamin $\mathrm{E}$ as a nanomicellar formulation for delivery of paclitaxel. Mol Pharm. 2013; 10:2880-2890. [PubMed: 23768151]

28. Zhang Y, Gu H, Yang Z, Xu B. Supramolecular hydrogels respond to ligand-receptor interaction. J Am Chem Soc. 2003; 125:13680-13681. [PubMed: 14599204]

29. Jayawarna V, Ali M, Jowitt TA, Miller AF, Saiani A, Gough JE, et al. Nanostructured Hydrogels for Three-Dimensional Cell Culture Through Self-Assembly of FluorenylmethoxycarbonylDipeptides. Adv Mater. 2006; 18:611-614.

30. Mahler A, Reches M, Rechter M, Cohen S, Gazit E. Rigid, Self-Assembled Hydrogel Composed of a Modified Aromatic Dipeptide. Adv Mater. 2006; 18:1365-1370.

31. Wang Y, Wang R, Lu X, Lu W, Zhang C, Liang W. Pegylated phospholipids-based self-assembly with water-soluble drugs. Pharm Res. 2010; 27:361-370. [PubMed: 20033475]

32. Mao J, Zhang H, Luo J, Li L, Zhao R, Zhang R, Liu G. New method for HPLC separation and fluorescence detection of malonaldehyde in normal human plasma. J Chromatogr B Analyt Technol Biomed Life Sci. 2006; 832:103-108.

33. Zhao Y, Alakhova DY, Kim JO, Bronich TK, Kabanov AV. A simple way to enhance Doxil® therapy: drug release from liposomes at the tumor site by amphiphilic block copolymer. J Control Release. 2013; 168:61-69. [PubMed: 23474033]

34. Hu CM, Zhang L. Therapeutic nanoparticles to combat cancer drug resistance. Curr Drug Metab. 2009; 10:836-841. [PubMed: 20214578]

35. Gottesman MM. Mechanisms of cancer drug resistance. Annu Rev Med. 2002; 53:615-627. [PubMed: 11818492]

36. Yuan H, Li X, Wu J, Li J, Qu X, Xu W, et al. Strategies to overcome or circumvent P-glycoprotein mediated multidrug resistance. Curr Med Chem. 2008; 15:470-476. [PubMed: 18289002]

37. Tijerina M, Fowers KD, Kopecková P, Kopecek J. Chronic exposure of human ovarian carcinoma cells to free or HPMA copolymer-bound mesochlorin e6 does not induce P-glycoprotein-mediated multidrug resistance. Biomaterials. 2000; 21:2203-2210. [PubMed: 10985494]

38. Desai PV, Sawada GA, Watson IA, Raub TJ. Integration of in silico and in vitro tools for scaffold optimization during drug discovery: predicting P-glycoprotein efflux. Mol Pharm. 2013; 10:1249_ 1261. [PubMed: 23363443]

39. Xu D, Kang H, Fisher M, Juliano RL. Strategies for inhibition of MDR1 gene expression. Mol Pharmacol. 2004; 66:268-275. [PubMed: 15266017]

40. Ogawara K, Un K, Tanaka K, Higaki K, Kimura T. In vivo anti-tumour effect of PEG liposomal doxorubicin (DOX) in DOX resistant tumour-bearing mice: Involvement of cytotoxic effect on vascular endothelial cells. J Control Release. 2009; 133:4-10. [PubMed: 18840484]

41. Luo J, Xiao K, Li Y, Lee JS, Shi L, Tan YH, et al. Well-defined, size-tunable, multifunctional micelles for efficient paclitaxel delivery for cancer treatment. Bioconjug Chem. 2010; 21:12161224. [PubMed: 20536174] 
42. Li Y, Xiao K, Luo J, Lee J, Pan S, Lam KS. A novel size-tunable nanocarrier system for targeted anticancer drug delivery. J Control Release. 2010; 144:314-323. [PubMed: 20211210]

43. Xiao K, Luo J, Li Y, Lee JS, Fung G, Lam KS. PEG-oligocholic acid telodendrimer micelles for the targeted delivery of doxorubicin to B-cell lymphoma. J Control Release. 2011; 155:272-281. [PubMed: 21787818]

44. Shirpoor A, Norouzi L, Khadem Ansari MH, Ilkhanizadeh B, Gharaaghaji R. Vasoprotective effect of vitamin E: rescue of ethanol-induced atherosclerosis and inflammatory stress in rat vascular wall. Int Immunopharmacol. 2013; 16:498-504. [PubMed: 23665315]

45. Buse J, El-Aneed A. Properties, engineering and applications of lipid-based nanoparticle drugdelivery systems: current research and advances. Nanomedicine (Lond). 2010; 5:1237-1260. [PubMed: 21039200]

46. Yen CT, Hwang TL, Wu YC, Hsieh PW. Design and synthesis of new N-(fluorenyl-9methoxycarbonyl) (Fmoc)-dipeptides as anti-inflammatory agents. Eur J Med Chem. 2009; 44:1933-1940. [PubMed: 19110343]

47. Chen X, Wang X, Wang Y, Yang L, Hu J, Xiao W, et al. Improved tumor-targeting drug delivery and therapeutic efficacy by cationic liposome modified with truncated bFGF peptide. J Control Release. 2010; 145:17-25. [PubMed: 20307599]

48. Ishida T, Shiraga E, Kiwada H. Synergistic antitumor activity of metronomic dosing of cyclophosphamide in combination with doxorubicin-containing PEGylated liposomes in a murine solid tumor model. J Control Release. 2009; 134:194-200. [PubMed: 19095022]

49. Schiffelers RM, Koning GA, ten Hagen TL, Fens MH, Schraa AJ, Janssen AP, et al. Anti-tumor efficacy of tumor vasculature-targeted liposomal doxorubicin. J Control Release. 2003; 91:115122. [PubMed: 12932643]

50. Maeng JH, Lee DH, Jung KH, Bae YH, Park IS, Jeong S, et al. Multifunctional doxorubicin loaded superparamagnetic iron oxide nanoparticles for chemotherapy and magnetic resonance imaging in liver cancer. Biomaterials. 2010; 31:4995-5006. [PubMed: 20347138]

51. Ma Y, Liu D, Wang D, Wang Y, Fu Q, Fallon JK, Yang X, He Z, Liu F. Combinational Delivery of Hydrophobic and Hydrophilic Anticancer Drugs in Single Nanoemulsions To Treat MDR in Cancer. Mol Pharm. 2014; 11:2623-2630. [PubMed: 24712391] 

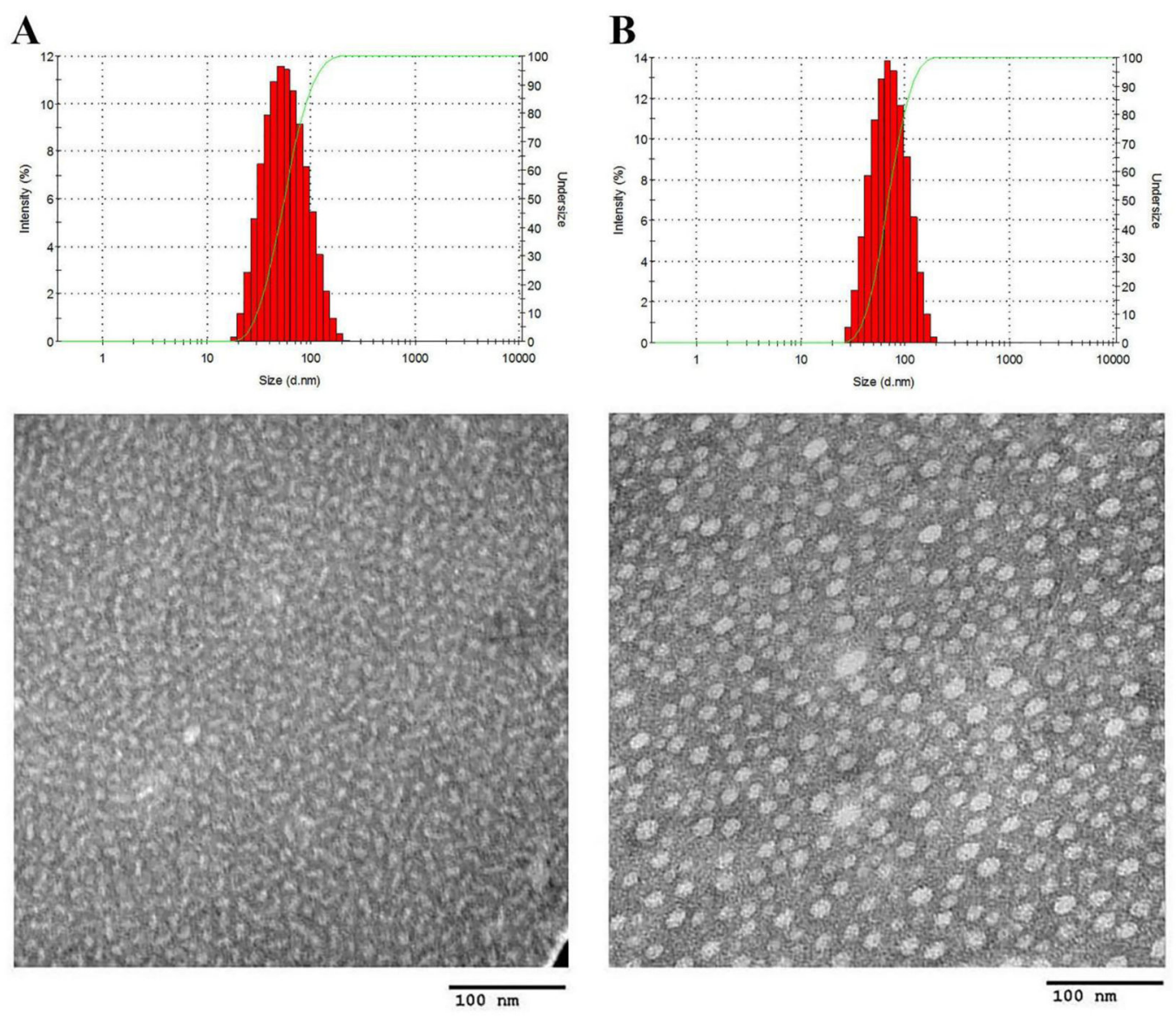

Fig. 1.

Size distribution and TEM of $\mathrm{PEG}_{5 \mathrm{~K}}-\mathrm{Fmoc}_{-\mathrm{VE}}(\mathrm{A})$, and $\mathrm{PEG}_{5 \mathrm{~K}}-\mathrm{Fmoc}-\mathrm{VE}_{2} / \mathrm{DOX}(0.1: 1$ $\mathrm{m} / \mathrm{m})(B)$. 


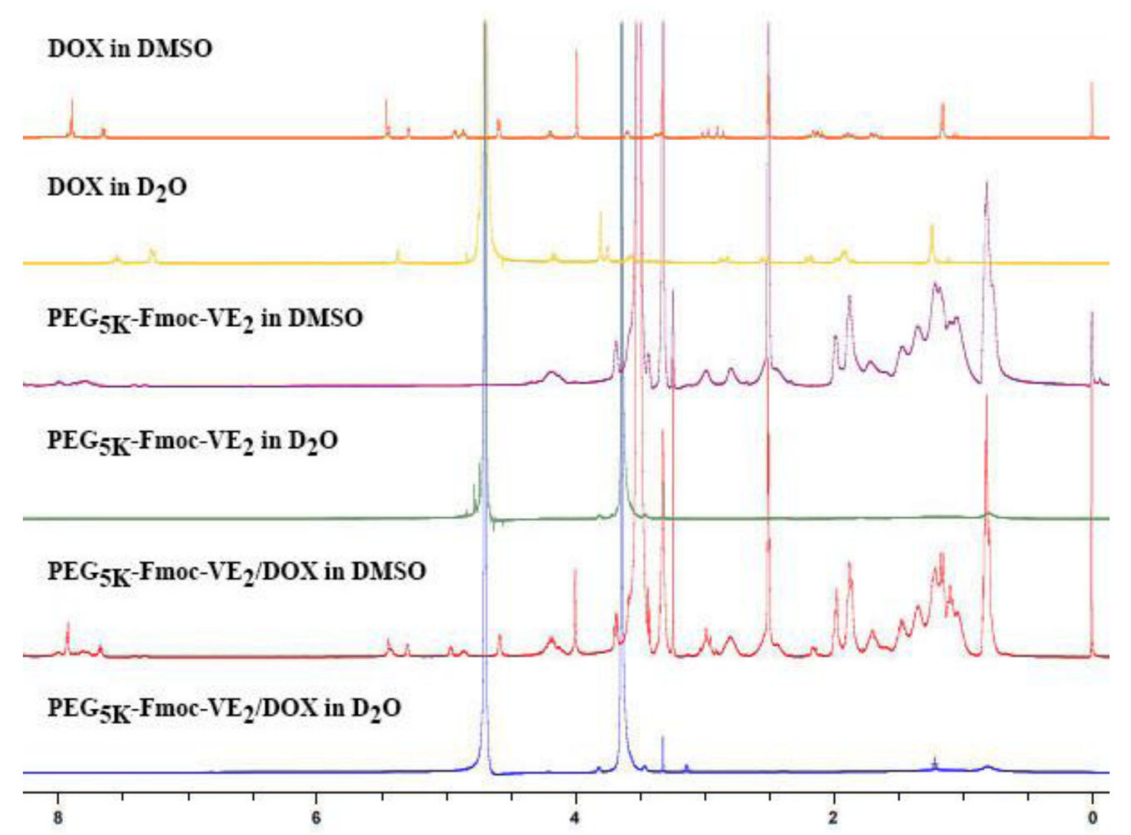

Fig. 2.

${ }^{1} \mathrm{NMR}$ spectra of free DOX in $\mathrm{D}_{2} \mathrm{O}, \mathrm{PEG}_{5 \mathrm{~K}}-\mathrm{Fmoc}_{-}-\mathrm{VE}_{2}$ in $\mathrm{D}_{2} \mathrm{O}$ or DMSO and DOX formulated in $\mathrm{PEG}_{5 \mathrm{~K}}-\mathrm{Fmoc}-\mathrm{VE}_{2}$ in $\mathrm{D}_{2} \mathrm{O}$ or DMSO. Concentration of DOX was $1 \mathrm{mg} / \mathrm{mL}$. 


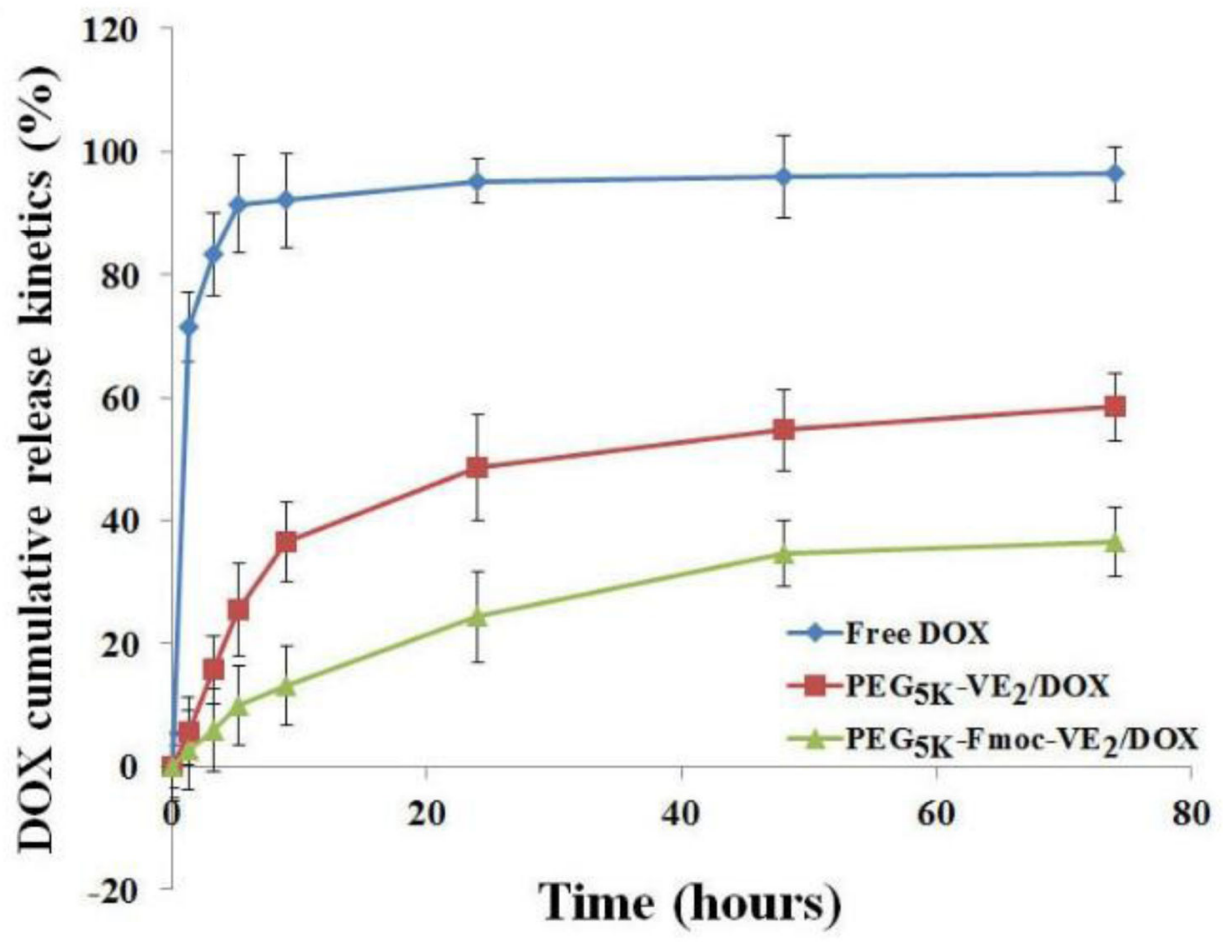

Fig. 3.

DOX cumulative release kinetics from free DOX, DOX-loaded $\mathrm{PEG}_{5 \mathrm{~K}}-\mathrm{VE}_{2}$ and DOXloaded $\mathrm{PEG}_{5 \mathrm{~K}}-\mathrm{Fmoc}-\mathrm{VE}_{2}$ micelles. DPBS $(\mathrm{PH}=7.4)$ containing $0.5 \%(\mathrm{~W} / \mathrm{V})$ Tween 80 was used as the release medium. DOX concentration was kept at $1 \mathrm{mg} / \mathrm{mL}$. Values reported are the means \pm SD for triplicate samples. 

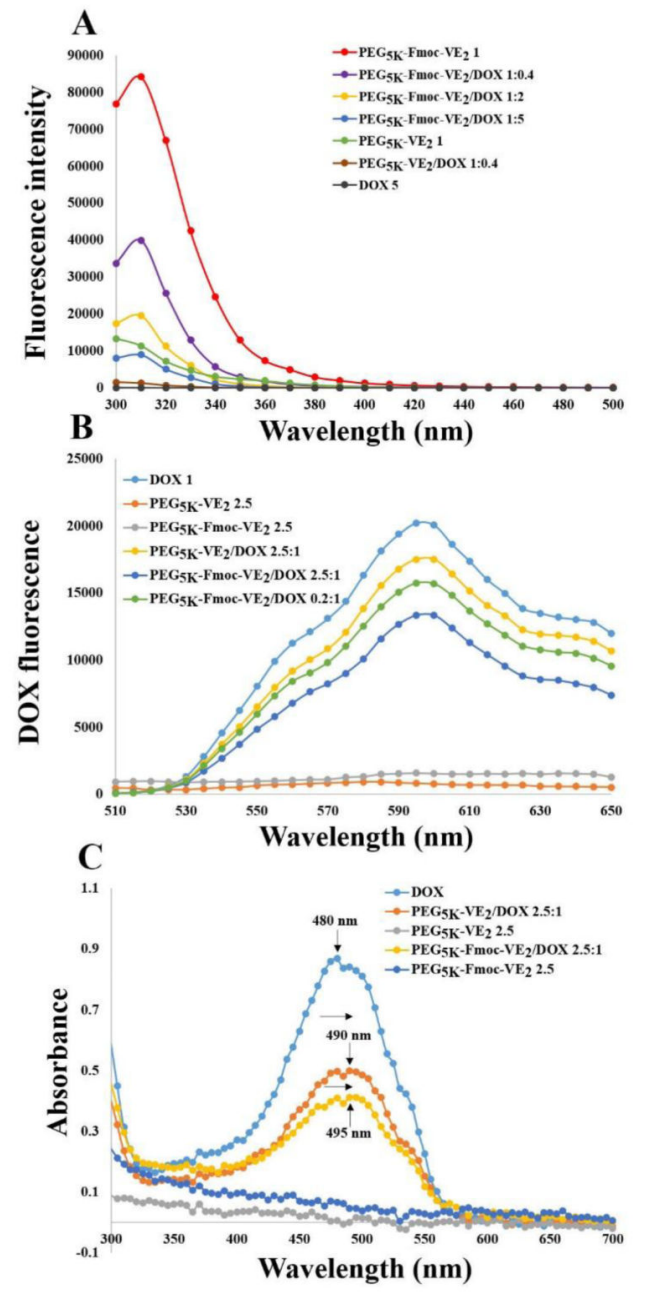

Fig. 4.

A: fluorescence intensity of the carriers. B: Fluorescence change of DOX. C: UVabsorbance of DOX. 

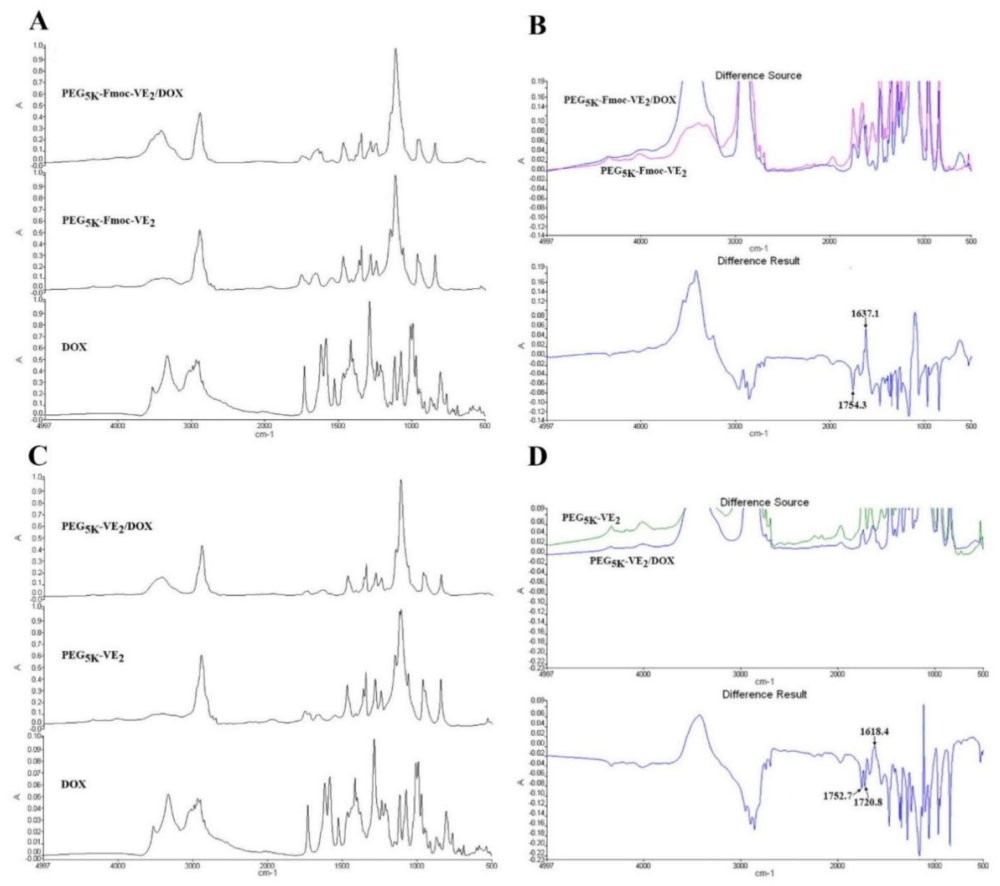

Fig. 5.

A: FT-IR of DOX, $\mathrm{PEG}_{5 \mathrm{~K}}-\mathrm{Fmoc}-\mathrm{VE}_{2}$, and $\mathrm{PEG}_{5 \mathrm{~K}}-\mathrm{Fmoc}_{\mathrm{V}} \mathrm{VE}_{2} / \mathrm{DOX}$. B: Difference of FTIR between $\mathrm{PEG}_{5 \mathrm{~K}}-\mathrm{Fmoc}-\mathrm{VE}_{2}$ and $\mathrm{PEG}_{5 \mathrm{~K}}-\mathrm{Fmoc}-\mathrm{VE}_{2} / \mathrm{DOX}$. C: FT-IR of DOX, $\mathrm{PEG}_{5 \mathrm{~K}^{-}}$ $\mathrm{VE}_{2}$, and $\mathrm{PEG}_{5 \mathrm{~K}}-\mathrm{VE}_{2} / \mathrm{DOX}$. D: Difference of FT-IR between $\mathrm{PEG}_{5 \mathrm{~K}}-\mathrm{VE}_{2}$ and $\mathrm{PEG}_{5 \mathrm{~K}}-\mathrm{VE}_{2} /$ DOX. 


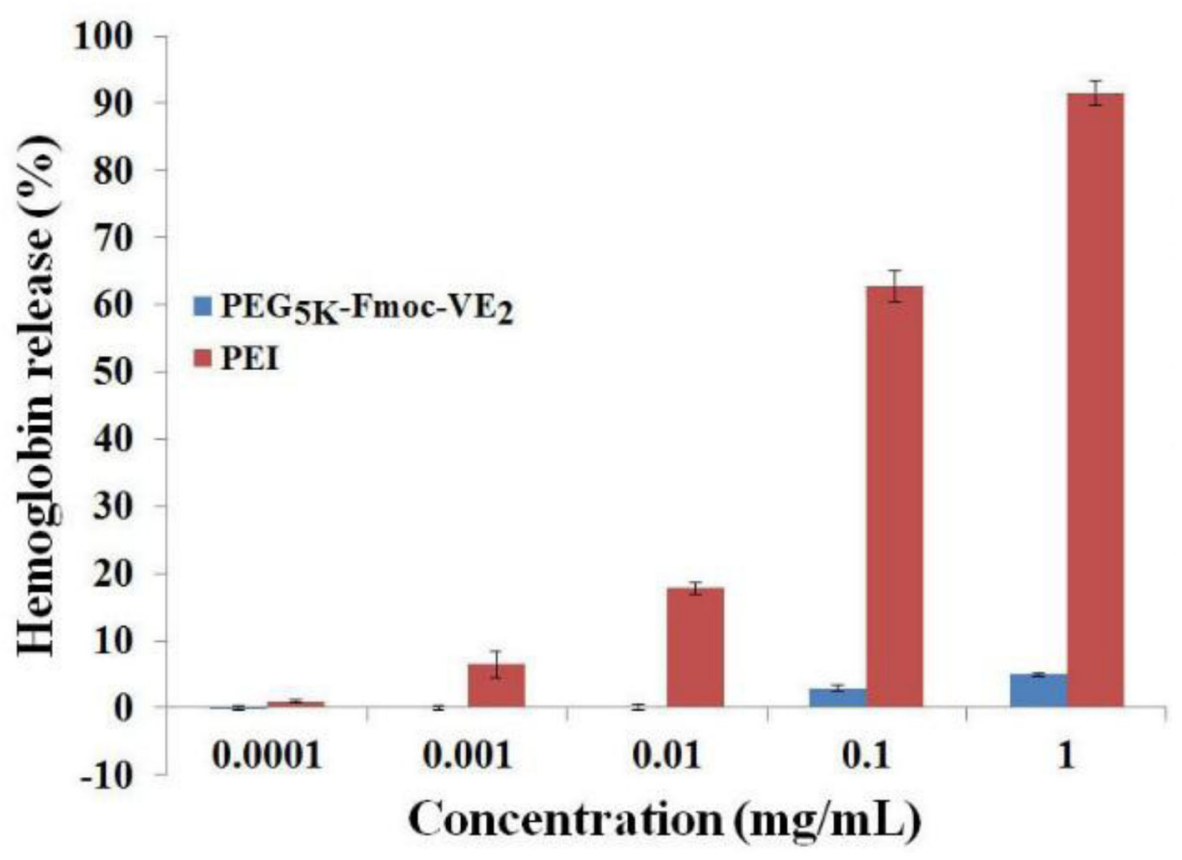

Fig. 6.

In vitro hemolysis assay of $\mathrm{PEG}_{5 \mathrm{~K}}-\mathrm{Fmoc}-\mathrm{VE}_{2}$ in comparison to PEI. $\mathrm{PEG}_{5 \mathrm{~K}}-\mathrm{Fmoc}-\mathrm{VE}_{2}$ and PEI of various concentrations were incubated with rat red blood cells (RBCs) for $4 \mathrm{~h}$ in an incubator shaker at $37{ }^{\circ} \mathrm{C}$. The degree of RBCs lysis was determined spectrophotometrically $(\lambda)$ according to the release of hemoglobin. 2\% Triton X-100 and DPBS were used as a positive and negative control, respectively. Values reported are the means \pm SD for triplicate samples. 


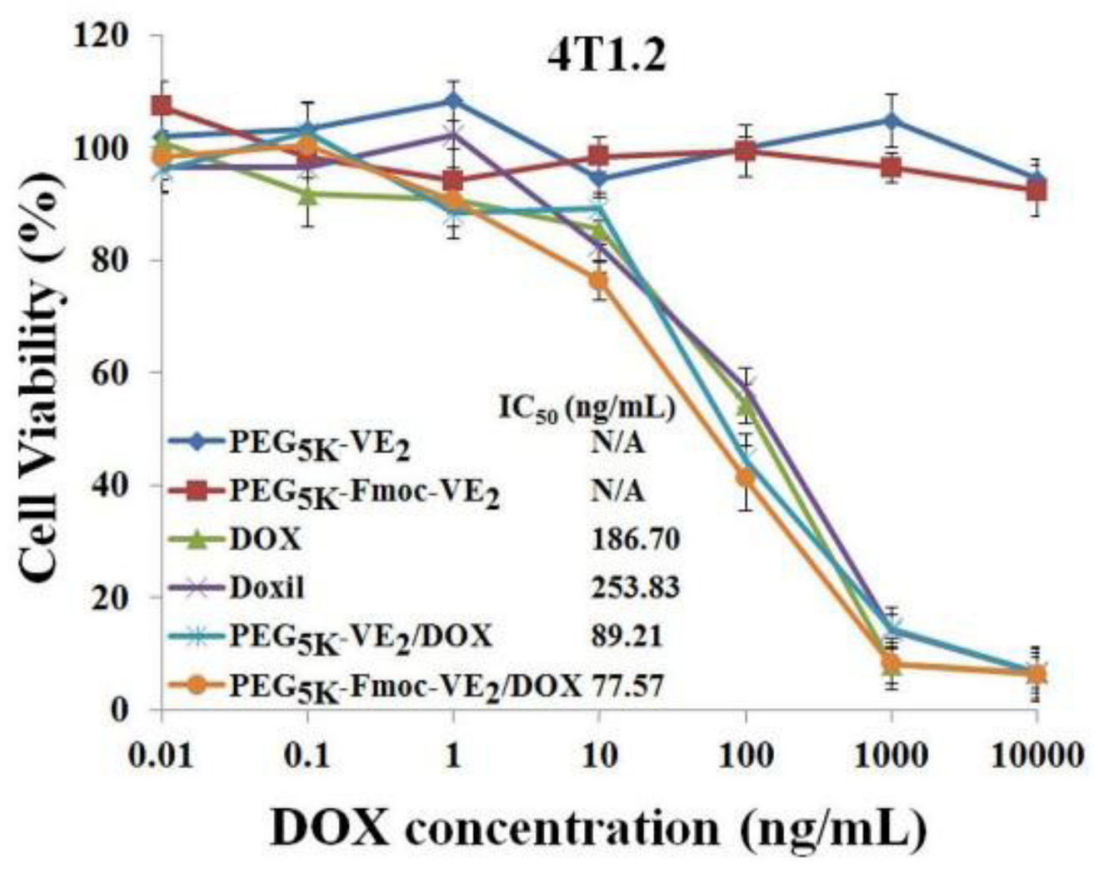

Fig. 7.

The cytotoxicity of $\mathrm{PEG}_{5 \mathrm{~K}}-\mathrm{VE}_{2} / \mathrm{DOX}$ and $\mathrm{PEG}_{5 \mathrm{~K}}-\mathrm{Fmoc}-\mathrm{VE}_{2} / \mathrm{DOX}$ against mouse breast cancer cell line, 4T1.2, compared to DOX and Doxil. Cells were treated with indicated concentrations of different DOX formulations for $72 \mathrm{~h}$ and cytotoxicity was then examined by MTT assay. Values reported are the means \pm SD for triplicate samples. 


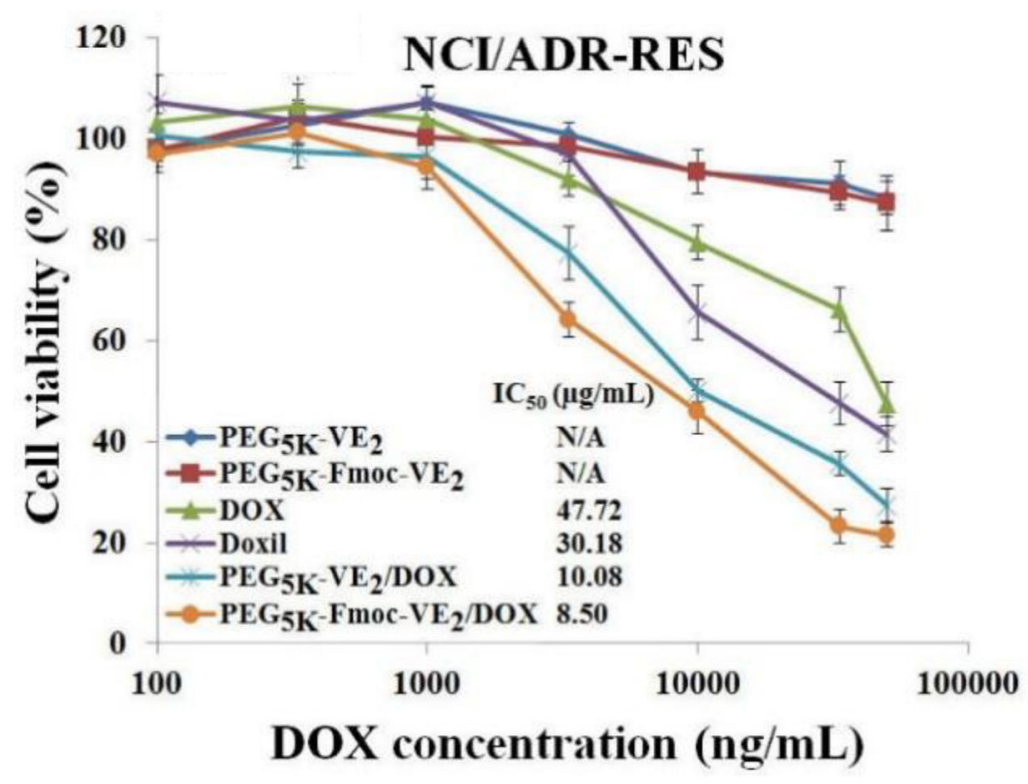

Fig. 8.

The anti-proliferative effect of $\mathrm{PEG}_{5 \mathrm{~K}}-\mathrm{VE}_{2} / \mathrm{DOX}$ and $\mathrm{PEG}_{5 \mathrm{~K}}-\mathrm{Fmoc}-\mathrm{VE}_{2} / \mathrm{DOX}$ in a drug resistant cell line, NCI/ADR-RES, in comparison to DOX and Doxil. Cells were challenged with indicated concentrations of different DOX formulations for $72 \mathrm{~h}$ and cytotoxicity was then determined by MTT assay. Values reported are the means \pm SD for triplicate samples. 

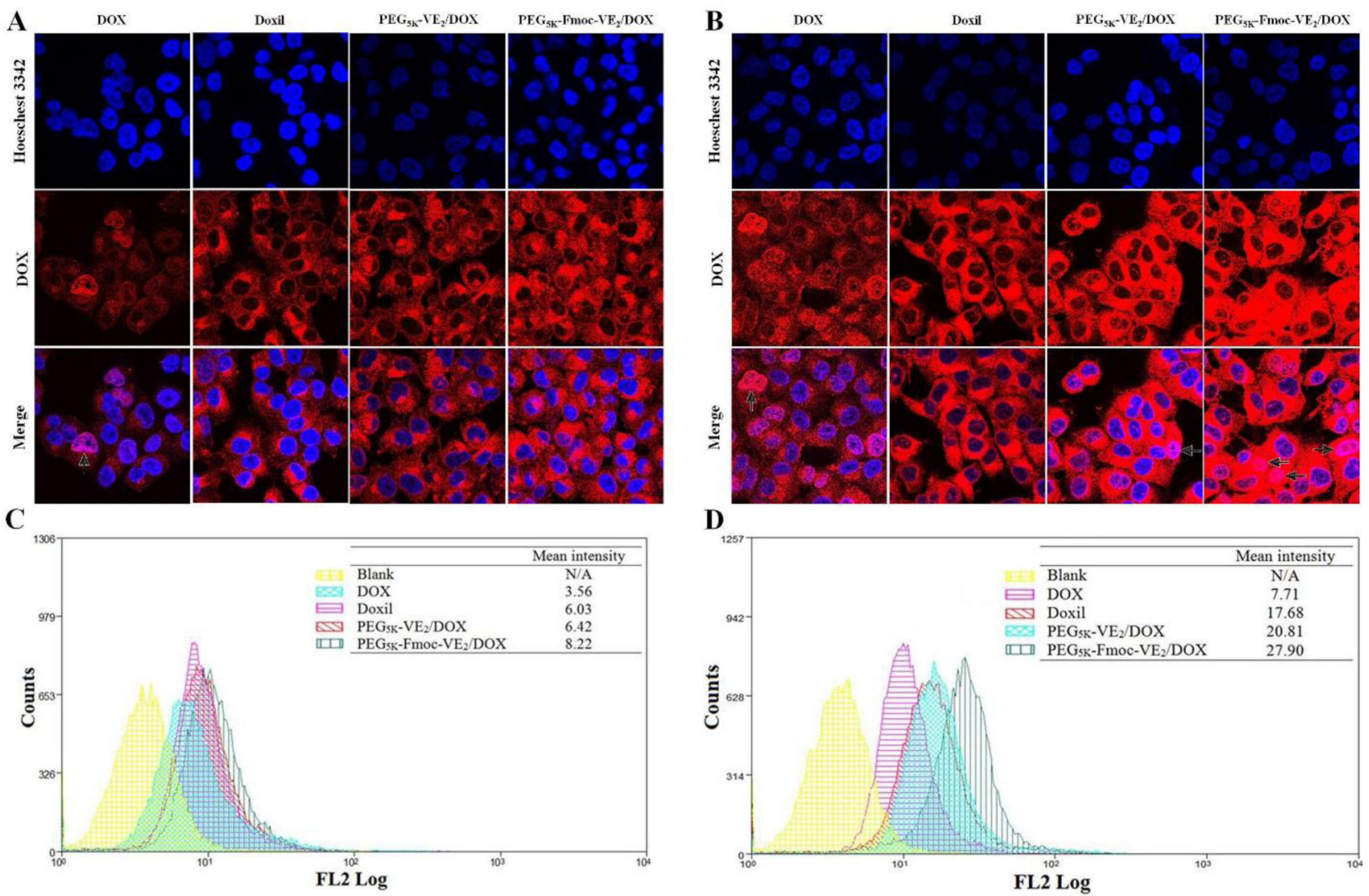

Fig. 9.

Confocal laser scanning microscopy (CLSM) images of NCI/ADR-RES cells incubated with free DOX, Doxil, $\mathrm{PEG}_{5 \mathrm{~K}}-\mathrm{VE}_{2} / \mathrm{DOX}$ and $\mathrm{PEG}_{5 \mathrm{~K}}-\mathrm{Fmoc}-\mathrm{VE}_{2} / \mathrm{DOX}$ for $1 \mathrm{~h}(\mathrm{~A})$ and $3 \mathrm{~h}$ (B); Quantitative analysis of uptake of different DOX formulations in NCI/ADR-RES cells after $1 \mathrm{~h}(\mathrm{C})$ and $3 \mathrm{~h}(\mathrm{D})$ treatment using flow cytometry. Arrows indicated the area that was colocalized by DOX. 


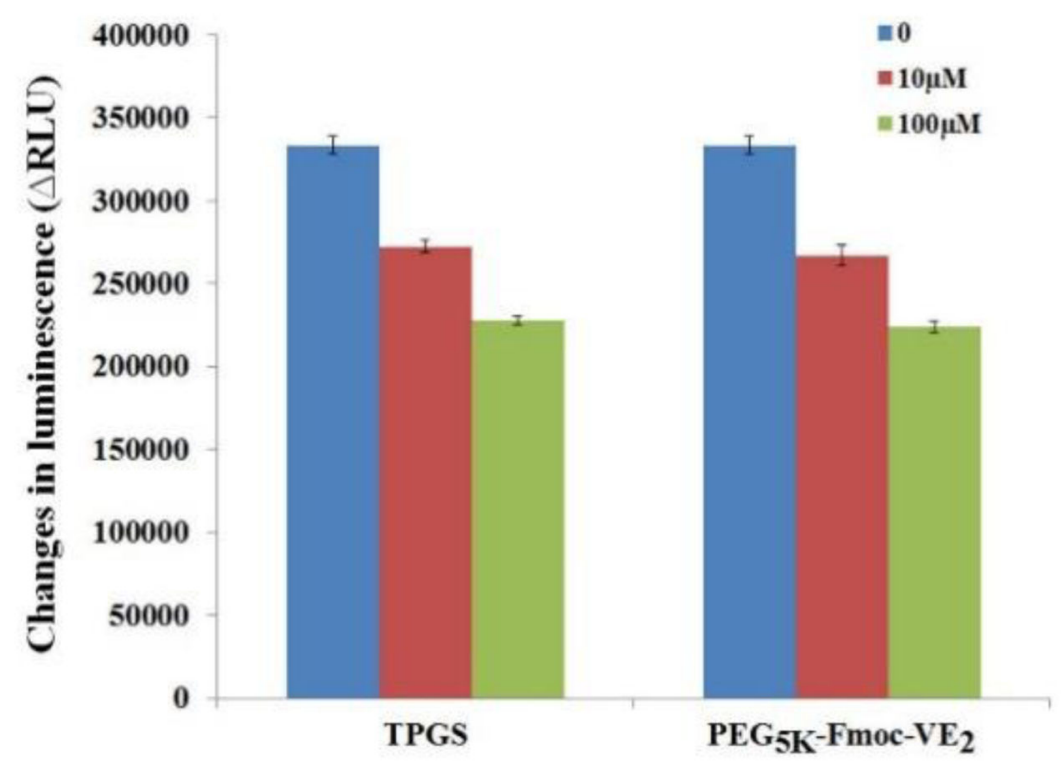

Fig. 10.

Inhibitory effect of TPGS and $\mathrm{PEG}_{5 \mathrm{~K}}-\mathrm{Fmoc}_{\mathrm{VE}}$ on verapamil-stimulated P-gp ATPase activity. Test samples containing verapamil $(50 \mu \mathrm{M})$ and $\mathrm{PEG}_{5 \mathrm{~K}}-\mathrm{Fmoc}-\mathrm{VE}_{2}$ (final concentrations at 10 and $100 \mu \mathrm{M}$, respectively) or $\mathrm{Na}_{3} \mathrm{VO}_{4}$ (a selective inhibitor of P-gp) were incubated with P-gp membrane for $5 \mathrm{~min}$ at $37^{\circ} \mathrm{C}$. The reaction was initiated by the addition of Mg/ATP followed by another 40 minutes' incubation at $37^{\circ} \mathrm{C}$. ATP detection reagent was then added and luminescence was examined. Values reported are the means \pm SD for triplicate samples. 


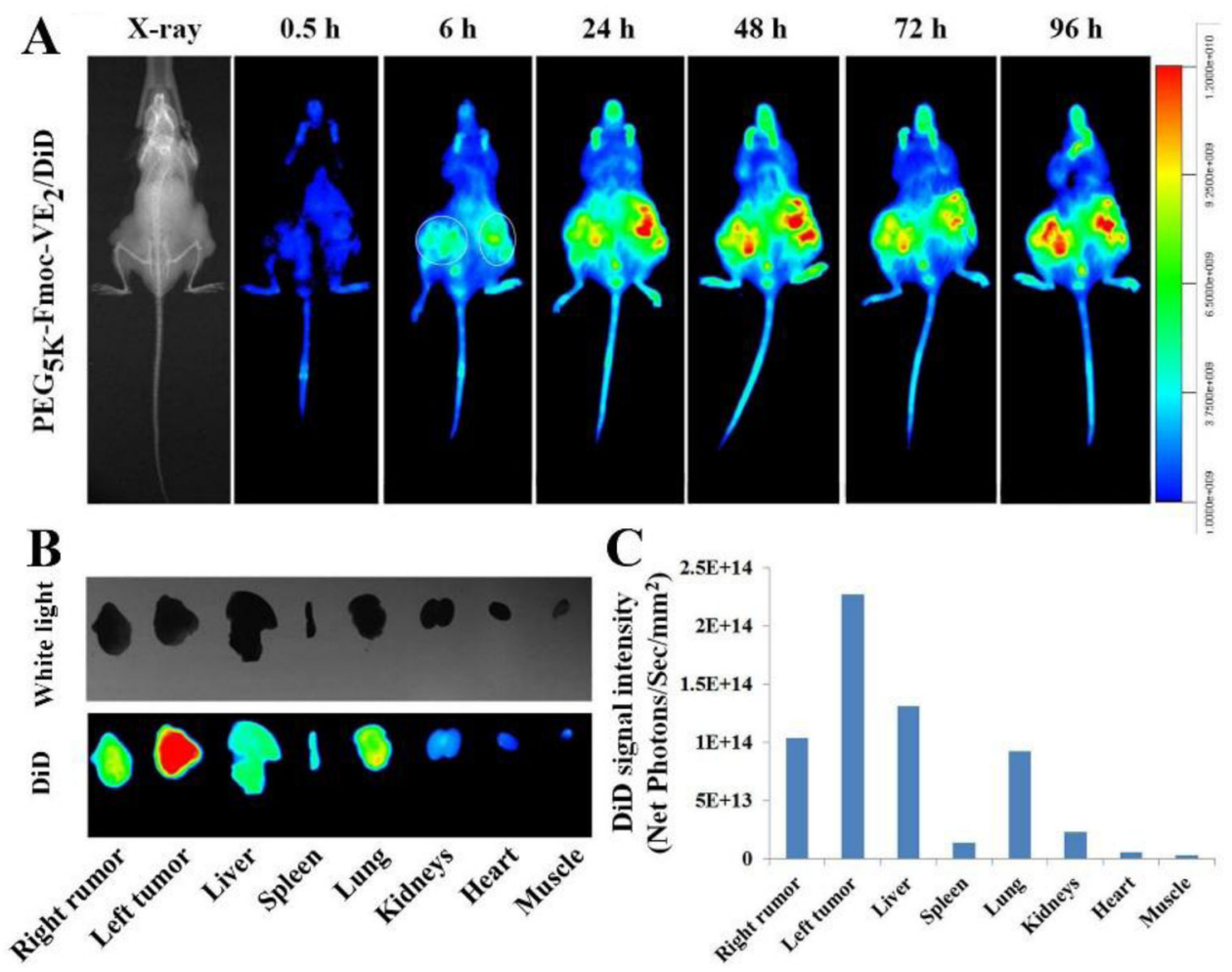

Fig. 11.

In vivo (A) and ex vivo (B) NIRF optical images of PC-3 tumor-bearing nude mice administered intravenously with DiD-loaded $\mathrm{PEG}_{5 \mathrm{~K}}-\mathrm{Fmoc}_{-} \mathrm{VE}_{2}$ nanoparticles. Tumors and major organs were excised for ex vivo imaging at $96 \mathrm{~h}$ post-injection and the quantitated DiD fluorescence intensity from different organs were presented (C). 

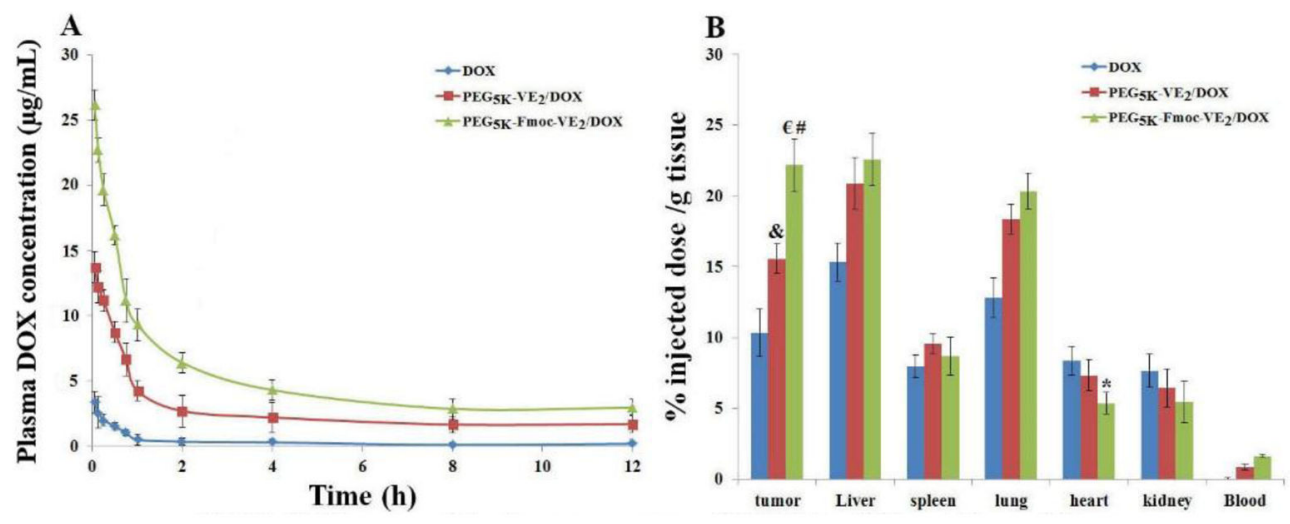

Fig. 12.

DOX pharmacokinetics (A) and biodistribution profiles (B) in 4T1.2-tumor bearing mice receiving intravenous administration of different DOX formulations at the dose of $5 \mathrm{mg} / \mathrm{kg}$. ${ }^{*} p<0.05$, compared to DOX and $\mathrm{PEG}_{5 \mathrm{~K}}-\mathrm{VE}_{2} / \mathrm{DOX} ;{ }^{€} p<0.005$, compared to DOX; ${ }^{*} p<$ 0.01 , compared to $\mathrm{PEG}_{5 \mathrm{~K}}-\mathrm{VE}_{2} / \mathrm{DOX} ; \& p<0.01$, compared to DOX. Values reported are the means \pm SD for triplicate samples. 

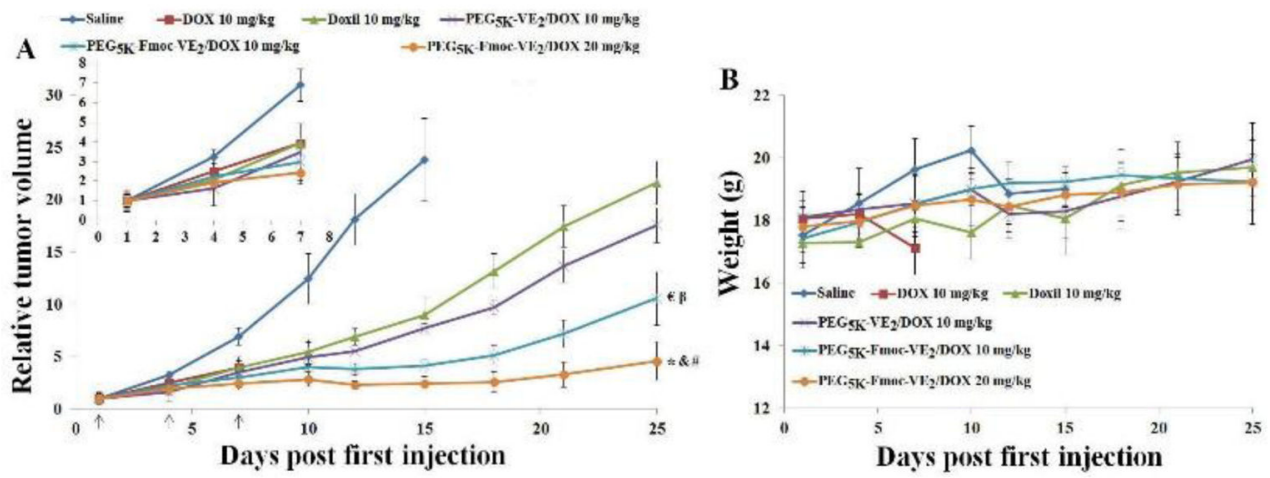

Fig. 13.

In vivo antitumor activity of different DOX formulations in 4T1.2 syngeneic mouse model.

Solid arrows indicate the i.v. administration. A: relative tumor volume. B: body weight. $* p<$ 0.0005, compared to Doxil. ${ }^{\&} p<0.001$, compared to $\mathrm{PEG}_{5 \mathrm{~K}}-\mathrm{VE}_{2} / \mathrm{DOX} ;{ }^{\#} p<0.05$, compared to $\mathrm{PEG}_{5 \mathrm{~K}}-\mathrm{Fmoc}-\mathrm{VE}_{2} / \mathrm{DOX}(10 \mathrm{mg} / \mathrm{kg}) ;{ }^{\boldsymbol{\epsilon}} p<0.05$, compared to $\mathrm{PEG}_{5 \mathrm{~K}}-\mathrm{VE}_{2} /$ DOX; ${ }^{\beta} p<0.005$, compared to Doxil. 

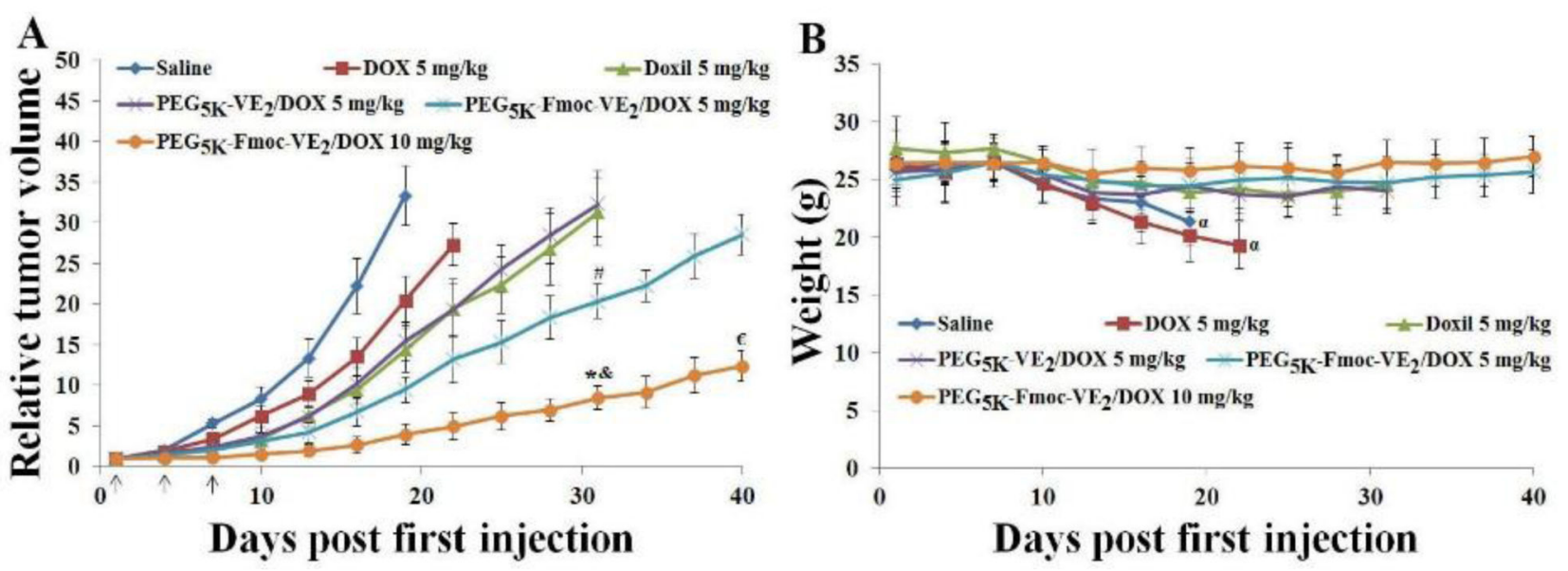

Fig. 14.

In vivo antitumor activity of various DOX formulations in PC-3 tumor-bearing mice. Solid arrows indicate the i.v. administration. A: relative tumor volume. B: body weight. ${ }^{*} p<$ 0.001 , compared to $\mathrm{PEG}_{5 \mathrm{~K}}-\mathrm{VE}_{2} / \mathrm{DOX}$ or Doxil on day $31 ;{ }^{\boldsymbol{\alpha}} p<0.01$, compared to $\mathrm{PEG}_{5 \mathrm{~K}^{-}}$ Fmoc-VE $2 / \mathrm{DOX}(5 \mathrm{mg} / \mathrm{kg})$ on day $31 ;{ }^{\#} p<0.01$, compared to $\mathrm{PEG}_{5 \mathrm{~K}}-\mathrm{VE}_{2} / \mathrm{DOX}$ or Doxil on day $31 ;{ }^{€} p<0.001$, compared to $\mathrm{PEG}_{5 \mathrm{~K}}-\mathrm{Fmoc} \mathrm{VE}_{2} / \mathrm{DOX}(5 \mathrm{mg} / \mathrm{kg})$ on day $40 ;{ }^{a} p<$ 0.05 , compared to day 1 . 


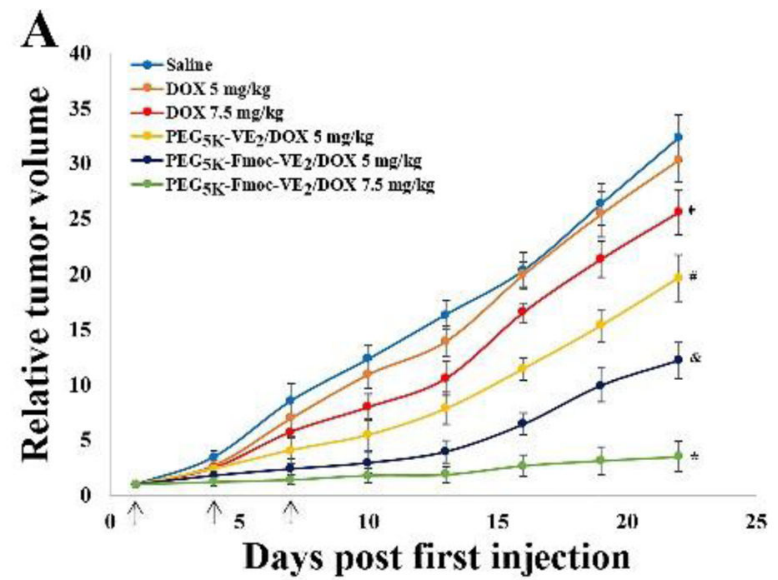

C

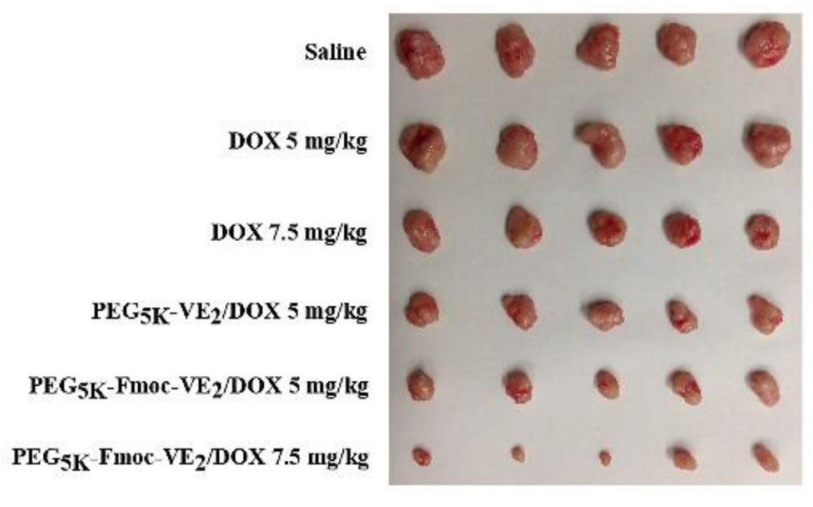

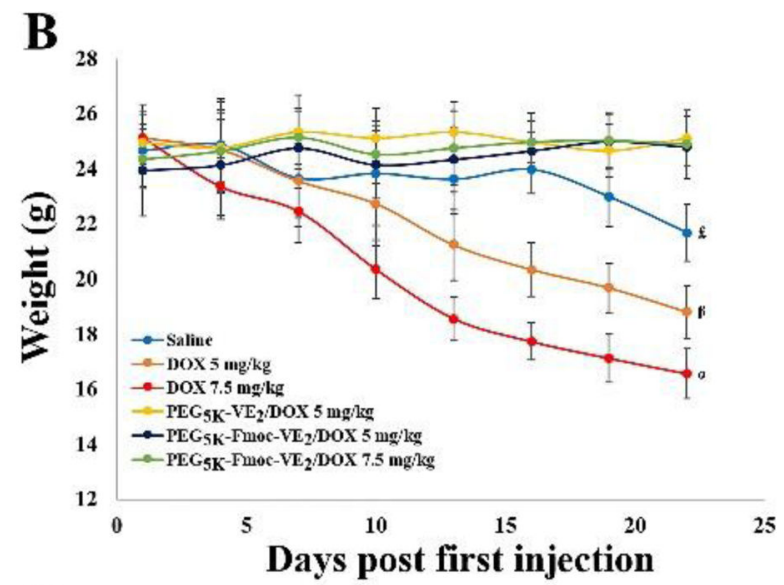

D

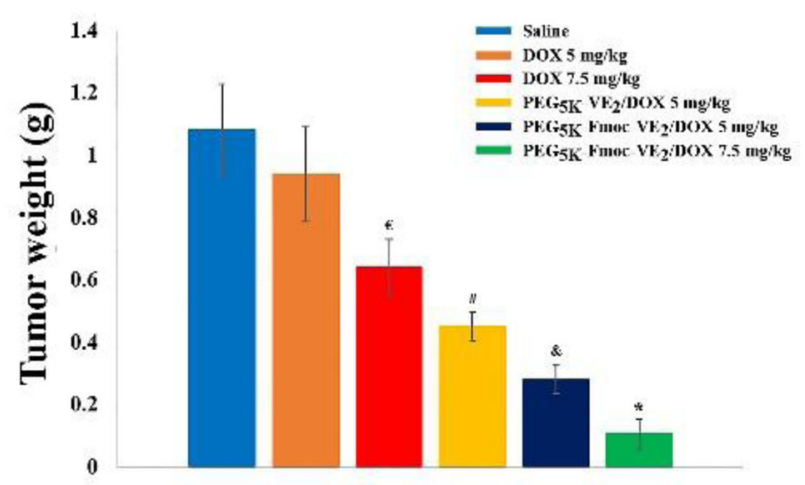

Fig. 15.

In vivo antitumor activity of varying DOX formulations in a drug-resistant xenograft tumor model, KB 8-5. Solid arrows indicate the i.v. injection. A: relative tumor volume. ${ }^{*} p<$ 0.002 , compared to $\mathrm{PEG}_{5 \mathrm{~K}}-\mathrm{Fmoc}-\mathrm{VE}_{2} / \mathrm{DOX}(5 \mathrm{mg} / \mathrm{kg}) ;{ }^{\boldsymbol{\alpha}} p<0.01$, compared to $\mathrm{PEG}_{5 \mathrm{~K}^{-}}$ $\mathrm{VE}_{2} / \mathrm{DOX}(5 \mathrm{mg} / \mathrm{kg}) ;{ }^{\#} p<0.05$, compared to DOX $(7.5 \mathrm{mg} / \mathrm{kg}) ;{ }^{\epsilon} p<0.05$, compared to DOX $(5 \mathrm{mg} / \mathrm{kg})$ or saline. B: body weight, ${ }^{\alpha} p<0.0005$, compared to day $1 ;{ }^{\beta} p<0.005$, compared to day $1 ;{ }^{\mathfrak{E}} p<0.05$, compared to day 1 . C: tumor images. D: tumor weight, ${ }^{*} p<$ 0.005 , compared to $\mathrm{PEG}_{5 \mathrm{~K}}-\mathrm{Fmoc}_{-} \mathrm{VE}_{2} / \mathrm{DOX}(5 \mathrm{mg} / \mathrm{kg}) ;{ }^{*} p<0.01$, compared to $\mathrm{PEG}_{5 \mathrm{~K}^{-}}$ $\mathrm{VE}_{2} / \mathrm{DOX}(5 \mathrm{mg} / \mathrm{kg}) ;{ }^{\#} p<0.001$, compared to DOX (7.5 mg/kg); ${ }^{€} p<0.05$, compared to DOX $(5 \mathrm{mg} / \mathrm{kg})$. 


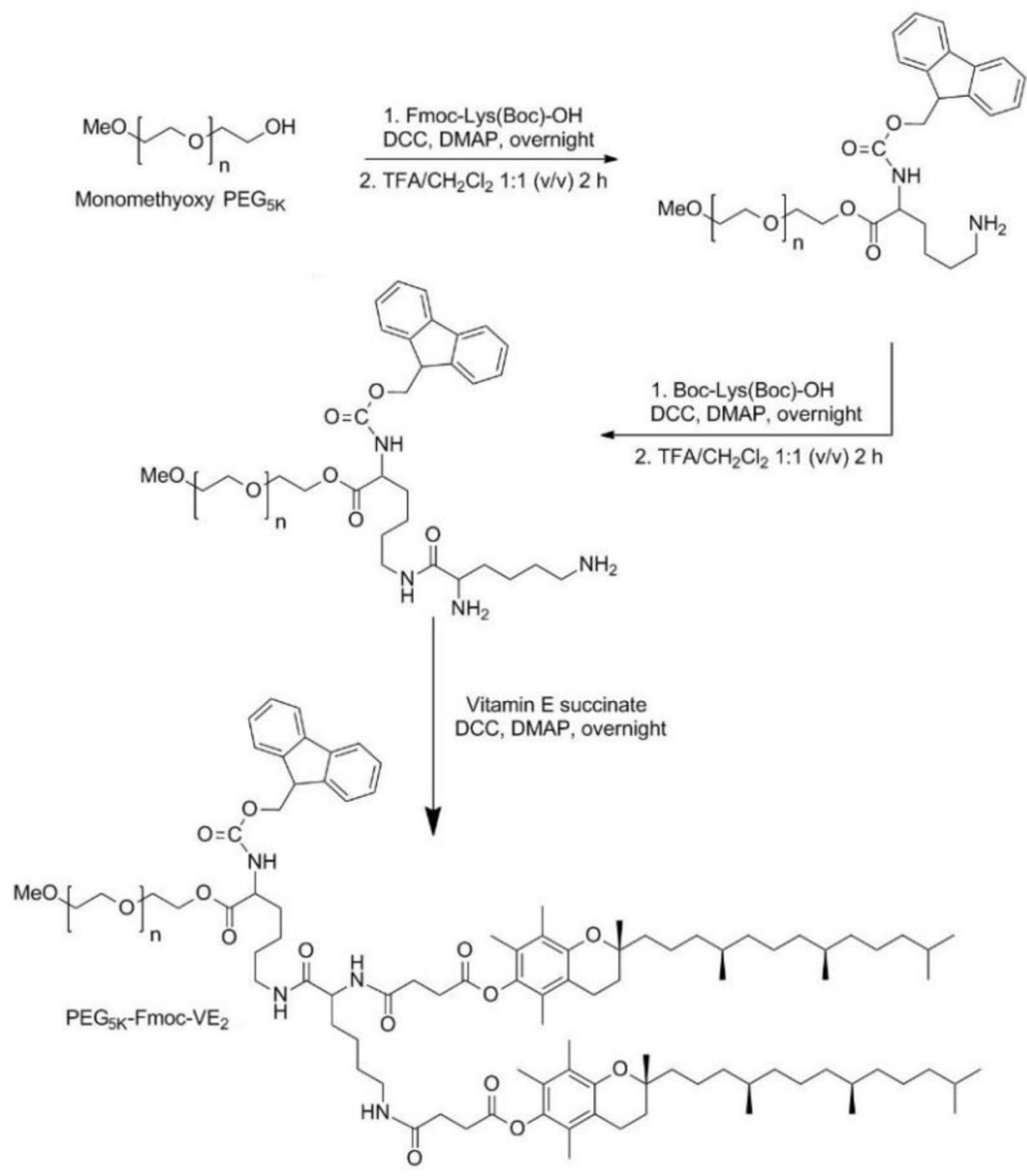

Scheme 1.

Synthetic route of $\mathrm{PEG}_{5 \mathrm{k}}-\mathrm{Fmoc}-\mathrm{VE}_{2}$ conjugate 
Table 3

MTD of DOX and DOX-loaded nanomicellar formulations

\begin{tabular}{cccc}
\hline Formulations & Does $(\mathbf{m g} / \mathbf{k g})$ & Animal death & Weight loss (\%) \\
\hline DOX & 5 & $0 / 3$ & 2.2 \\
& 10 & $0 / 3$ & 7.8 \\
DOX-loaded PEG $_{5 \mathrm{~K}}-\mathrm{VE}_{2}$ & 15 & $2 / 3$ & $\mathrm{~N} / \mathrm{A}$ \\
& 5 & $0 / 3$ & 0.9 \\
& 10 & $0 / 3$ & -1.8 \\
DOX-loaded $\mathrm{PEG}_{5 \mathrm{~K}}-\mathrm{Fmoc}-\mathrm{VE}_{2}$ & 15 & $0 / 3$ & 3.9 \\
& 20 & $0 / 3$ & 6.2 \\
& 30 & $3 / 3$ & $\mathrm{~N} / \mathrm{A}$ \\
& 10 & $0 / 3$ & -2.2 \\
& 15 & $0 / 3$ & 0.2 \\
& 20 & $0 / 3$ & -1.3 \\
& 25 & $0 / 3$ & 3.5 \\
& 30 & $0 / 3$ & 7.4 \\
& 35 & $2 / 3$ & N/A \\
\hline
\end{tabular}




\section{Table 4}

Tumor growth inhibition rate (IR) in 4T1.2 tumor bearing mice.

\begin{tabular}{cc}
\hline Different DOX formulations & IR (\%) \\
\hline Doxil $10 \mathrm{mg} / \mathrm{kg}$ & 62.24 \\
$\mathrm{PEG}_{5 \mathrm{~K}}-\mathrm{VE}_{2} / \mathrm{DOX} 10 \mathrm{mg} / \mathrm{kg}$ & 67.73 \\
$\mathrm{PEG}_{5 \mathrm{~K}}-\mathrm{Fmoc}-\mathrm{VE}_{2} / \mathrm{DOX} 10 \mathrm{mg} / \mathrm{kg}$ & 82.63 \\
$\mathrm{PFG}_{5 \mathrm{~K}}-\mathrm{Fmoc}-\mathrm{VE}_{2} / \mathrm{DOX} 20 \mathrm{mg} / \mathrm{kg}$ & 89.77 \\
\hline
\end{tabular}

$I R(\%)=(1-$ relative tumor volume in the treated group $\div$ relative tumor volume in the saline group $) \times 100 \%$

IR (\%) was calculated based on the RTV on day 15 (Mice in saline group died after day 15. Mice in DOX group died after third injection due to severe toxicity) 


\section{Table 5}

Tumor growth inhibition rate (IR) in PC-3 tumor bearing mice.

\begin{tabular}{cc}
\hline Different DOX formulations & IR (\%) \\
\hline DOX $5 \mathrm{mg} / \mathrm{kg}$ & 38.72 \\
Doxil $5 \mathrm{mg} / \mathrm{kg}$ & 56.98 \\
$\mathrm{PEG}_{5 \mathrm{~K}}-\mathrm{VE}_{2} / \mathrm{DOX} 5 \mathrm{mg} / \mathrm{kg}$ & 53.71 \\
$\mathrm{PEG}_{5 \mathrm{~K}}-\mathrm{Fmoc}_{\mathrm{V}} \mathrm{VE} / \mathrm{DOX} 5 \mathrm{mg} / \mathrm{kg}$ & 71.64 \\
$\mathrm{PEG}_{5 \mathrm{~K}}-\mathrm{Fmoc}-\mathrm{VE}_{2} / \mathrm{DOX} 10 \mathrm{mg} / \mathrm{kg}$ & 88.10 \\
\hline
\end{tabular}

$I R(\%)=(1-$ relative tumor volume in the treated group $\div$ relative tumor volume in the saline group $) \times 100 \%$

$\operatorname{IR}(\%)$ was calculated based on the RTV on day 19 (Mice in saline group died after day 19) 


\section{Table 6}

Tumor growth inhibition rate (IR) in KB 8-5 tumor bearing mice.

\begin{tabular}{cc}
\hline Different DOX formulations & IR $(\%)$ \\
\hline DOX $5 \mathrm{mg} / \mathrm{kg}$ & 6.13 \\
DOX $7.5 \mathrm{mg} / \mathrm{kg}$ & 20.91 \\
$\mathrm{PEG}_{5 \mathrm{~K}}-\mathrm{VE}_{2} / \mathrm{DOX} 5 \mathrm{mg} / \mathrm{kg}$ & 39.15 \\
$\mathrm{PEG}_{5 \mathrm{~K}}-\mathrm{Fmoc}_{-} \mathrm{VE}_{2} / \mathrm{DOX} 5 \mathrm{mg} / \mathrm{kg}$ & 62.15 \\
$\mathrm{PEG}_{5 \mathrm{~K}}-\mathrm{Fmoc}_{-} \mathrm{VE}_{2} / \mathrm{DOX} 7.5 \mathrm{mg} / \mathrm{kg}$ & 89.21 \\
\hline
\end{tabular}

$\operatorname{IR}(\%)=(1-$ relative tumor volume in the treated group $\div$ relative tumor volume in the saline group $) \times 100 \%$

$\operatorname{IR}(\%)$ was calculated based on the RTV on day 22 